\title{
A longitudinal study of socioeconomic status, family processes, and child adjustment from preschool until early elementary school: the role of social competence
}

\author{
Rikuya Hosokawa ${ }^{1,2^{*}}$ and Toshiki Katsura ${ }^{2}$
}

\begin{abstract}
Objective: Using a short-term longitudinal design, this study examined the concurrent and longitudinal relationships among familial socioeconomic status (SES; i.e., family income and maternal and paternal education levels), marital conflict (i.e., constructive and destructive marital conflict), parenting practices (i.e., positive and negative parenting practices), child social competence (i.e., social skills), and child behavioral adjustment (i.e., internalizing and externalizing problems) in a comprehensive model.

Methods: The sample included a total of 1604 preschoolers aged 5 years at Time 1 and first graders aged 6 years at Time 2 (51.5\% male). Parents completed a self-reported questionnaire regarding their SES, marital conflict, parenting practices, and their children's behavioral adjustment. Teachers also evaluated the children's social competence.

Results: The path analysis results revealed that Time 1 family income and maternal and paternal education levels were respectively related to Time 1 social skills and Time 2 internalizing and externalizing problems, both directly and indirectly, through their influence on destructive and constructive marital conflict, as well as negative and positive parenting practices. Notably, after controlling for Time 1 behavioral problems as mediating mechanisms in the link between family factors (i.e., SES, marital conflict, and parenting practices) and behavioral adjustment, Time 1 social skills significantly and inversely influenced both the internalization and externalization of problems at Time 2 .

Conclusions: The merit of examining SES, marital conflict, and parenting practices as multidimensional constructs is discussed in relation to an understanding of processes and pathways within families that affect child mental health functioning. The results suggest social competence, which is influenced by the multidimensional constructs of family factors, may prove protective in reducing the risk of child maladjustment, especially for children who are socioeconomically disadvantaged.
\end{abstract}

Keywords: Socioeconomic status, Marital conflict, Parenting practice, Social competence, Behavioral problems, Preschool children

\section{Background}

An extensive amount of research has consistently found associations between childhood socioeconomic status (SES) and mental health functioning [1-3], with marital

\footnotetext{
*Correspondence: rikuya@med.nagoya-cu.ac.jp

1 School of Nursing, Nagoya City University, Mizuho-cho, Mizuho-ku,

Nagoya 467-8601, Japan

Full list of author information is available at the end of the article
}

conflict and parenting practices seeming to mediate these associations. SES is a construct that consists of multiple dimensions of social position $[4,5]$. Previous related empirical and theoretical research has focused on economic and educational aspects as SES indicators. Family income has been associated with children's developmental outcomes, as have parental educational levels [6-12]. However, despite the many studies conducted in this area, few have simultaneously investigated the influence 
of family income and maternal and paternal education levels as predictors in the relationships between SES, family processes (e.g., marital conflict and parenting practices), and child mental health functioning.

Additionally, despite extensive studies concerning the relationships between SES, family processes, and child mental health functioning, most have only minimally considered the effects of the positive dimensions of marital conflict and parenting practices (e.g., constructive marital conflict and positive parenting practices), rather than the negative dimensions thereof (e.g., destructive marital conflict and negative parenting practices), as mediators in the link between SES and child mental health functioning $[7,13-16]$. Moreover, a limitation of previous empirical work concerning these associations (i.e., SES, family processes, and child mental health functioning) is that these studies focused on negative developmental outcomes (e.g., internalizing and externalizing problems) $[17,18]$. Further studies examining positive dimensions of child mental health functioning, especially the issue of social competence, are needed. Social competence, which is defined as an individual's ability to act in a socially appropriate manner $[19,20]$, has received comparatively less attention as a mediator in the link between SES, family processes, and child behavioral adjustment, despite preliminary evidence suggesting it may be an important indicator.

When considering the complex relationships between these variables, it is important to consider independent associations, while controlling for other variables. However, previous studies have primarily examined individual relationships between different types of SES, marital conflict, and parenting practices, as well as child social competence and behavioral adjustment, without considering these associations in a comprehensive model. Therefore, this study examined mediators of the associations between SES and children's functioning in greater detail. Specifically, destructive and constructive marital conflict, negative and positive parenting practices, and child social skills were investigated as mediators in the associations between SES indicators, including family income and parental education levels, and children's internalizing and externalizing behaviors in a unified model. Regarding social skills, we especially focused on the mediating role of social competence in the relationships between family factors (i.e., SES, marital conflict, and parenting attitude) and child behavioral problems, from preschool to the first grade.

\section{Socioeconomic status and child adjustment}

Research in the past decade has shown that SES is an important contextual factor that strongly predicts child outcomes [1-3]. Extensive research has shown that
SES affects the well-being and development of children, including their internalizing (e.g., anxiety, depression, and withdrawal) and externalizing (e.g., aggression, opposition, and hyperactivity) symptoms, as well as their cognitive and language development [1, 3, 21-27].

It has been well documented that economic problems, such as low income and financial instability, adversely influence inter-parental and parent/child interactions, which in turn are related to a range of harmful outcomes for child development [28]. Studies have shown that economic problems are associated with destructive parental interactions that predict increased domestic problems and lower levels of marital quality. Furthermore, it has also been shown that economic problems place children at an increased risk of exposure to family conflict [7, 2932]. Economic problems are also predictors of negative parenting, including lack of warmth and involvement, parental harshness, and authoritarian parenting methods $[28,33-36]$.

The family stress model (FSM), which was proposed by Conger et al., explains the relationships among SES, marital conflict, and parenting style, while also providing solid evidence for the negative effects of family economic problems on both parents and children [15, 37]. The FSM proposes that economic hardship predicts economic pressure, which in turn exacerbates emotional distress (e.g., depression, anxiety, anger, and alienation) for both parents [37]. In turn, parental emotional distress has a direct, negative impact on the parents' relationships with each other, as indicated by conflict. This conflict then spills over into parent/child relationships, in the form of negative parenting, resulting in harsh, uninvolved, and/ or inconsistent child-rearing practices; these parenting styles are associated with an increase in negative outcomes for children [29, 37-39].

Educational status and economic aspects are typical quantitative SES indicators [4, 5]. Many previous studies have focused on the educational aspects of SES in the relationship between SES and child development, with parental educational levels being associated with child developmental outcomes [1, 2, 10-12, 25, 26]. However, despite the many studies completed in this area, few have simultaneously investigated the influence of multiple components of SES, including family income, and maternal and paternal education levels, as predictors in the relationships among SES, family processes, and child mental health functioning. In several studies that include both educational and economic aspects of SES indicators, educational status has often either previously been used as a control variable, or it has been combined with income in the construction of an overall index of SES indicators [6, 7]. Furthermore, a limitation of previous empirical work on the FSM is that studies have also 
focused exclusively on the economic aspect of SES in the relationship between SES and family processes, dedicating little research attention to the educational aspects of SES [28]. It is well known that education is an important predictor of family income across the life course [40]. Therefore, it may be reasonable to expect the influence of educational status on parental interactions and parent/ child interactions to be indirect and mediated by economic well-being.

Education is an important component of SES that helps identify a social class or position, and has been linked to individual competence [4]. Higher education is likely to enhance various individual skills for competent functioning, such as problem-solving skills, cognitive skills, and capacity to cope with change. People with higher levels of education tend to be able to solve problems that are more complex and perform jobs with more autonomy and creativity [41-44]. Moreover, educational achievement provides persons with more employment opportunities, enhances their ability to make significant contributions to their fields, and demonstrates significant positive associations with occupational prestige and income [40, 4547]. Furthermore, according to human capital theory, the education level of an individual's spouse also helps accumulate human capital and has an important impact on economic outcomes $[48,49]$. For example, a spouse with a higher education might provide constructive advice and information that can affect career and decision making in the family, such as consumption, fertility, and where to live [50-52]. Additionally, spouses are likely to affect each other through values, attitudes, and other abilities associated with education. Many studies have revealed common findings that the education level of an individual's spouse is positively correlated with the individual's earnings. Especially, numerous studies have suggested that a wife's education affects her husband's earnings [51-56], and vice versa. Additionally, other studies have shown that an individual's earnings are positively correlated with their spouse's education level $[53,57]$. This correlation might be due to marital matching, as individuals that are more productive are more likely to marry better-educated individuals.

However, despite the fact that parental education levels strongly interact with income, education levels and economic conditions could have different effects on family processes and child mental health functioning, possibly acting through different pathways. Regarding the relationship between educational level and marital relationship, higher education is likely to help parents to strengthen their communication and analytical skills, allowing for more effective problem solving between parents [44, 50,58]. Moreover, higher education is also likely to enhance self-control and coping mechanisms of parents, possibly increasing the positive association between education and psychological well-being [58]. Consequently, parental education levels might positively affect marital relationship through parental psychological well-being [44, 59-61]. A large amount of evidence for the beneficial nature of education on marriage exist, as studies have demonstrated a negative relationship between parental educational levels and marital conflict [62], a positive association between educational attainment and greater marital satisfaction [30, 63], and higher levels of educational attainment are associated with greater marital stability [64, 65].

In addition, previous research has suggested that parental education is the strongest and most important predictor of parenting behavior [66]. Regarding the relationship between educational level and parent/ child interactions, higher education is likely to promote the ability to process information, and enable parents to acquire more knowledge and skills about childrearing and child development, allowing parents with higher education to use more effective strategies for childrearing [66-68]. Moreover, as mentioned above, a higher level of education is likely to boost parental psychological wellbeing, which, in turn, could positively influence parenting style [69-71]. Many studies found that higher maternal education levels are associated with more supportive parenting [72, 73], which is also associated with positive cognitive, behavioral, emotional, and physical child outcomes [74-77]. While few studies have investigated the influence of paternal education levels on fathers' involvement in childrearing, some studies have found paternal education levels to be somewhat associated with parent/ child interactions. For example, several studies revealed that fathers with higher educational attainment tend to be more involved, show more positive engagement, and be more accessible to their children than fathers with a lower education level [78-80]. However, other studies have found little association between paternal educational attainment and fathers' involvement, after controlling for factors such as family income and maternal education level [6-9]. As there are conflicting results in the literature regarding the influence of paternal education level on parental involvement, it is possible that parental education levels may influence parenting attitudes directly, or they may do so indirectly through family economic factors or other SES indicators. Given this information, we are unable to form strong expectations regarding the possible pathways of how both maternal and paternal education levels may influence childhood mental health problems.

When considering the complex relationships in the above-mentioned variables, it is important to consider independent associations, while controlling for other SES 
variables. However, few previous studies have primarily examined individual relationships between SES, including family income and parental educational levels, interparental interactions, parent/child interactions, and/ or child mental health functioning, taking into account associations in a comprehensive model. Therefore, investigations into SES, including family income and parental educational levels, are needed to clarify how each SES indicator flows through the family processes to influence child development. Studying individual markers of SES, including family income and maternal and paternal education, enables us to study the unique and combined contributions of family income and parental education towards family functioning and child adjustment.

\section{Family processes and child adjustment}

As mentioned earlier, the FSM has shown that economic hardship predicts greater economic pressure, in turn exacerbating emotional distress among parents, which then negatively affects their relationship with each other, as indicated by parental relationship conflict $[29,39]$. This marital conflict spills over into parent/child relationships, which are characterized by more hostile, harsh, emotionally neglectful parenting, and less warmth. These types of relationships are associated with more negative outcomes (e.g., emotional, behavioral, mental, and physical health problems) in childhood and adulthood [7, 15, 16].

The "spillover hypothesis" has been proposed to explain this relationship between marital conflict and child outcomes. According to this hypothesis, the negativity and positivity experienced in the inter-parental relationship transfer to the parent/child relationship, affecting child outcomes [17, 18, 81-83]. The hypothesis further posits that destructive marital conflict, such as verbal and physical aggression, requires excessive energy that makes parents less emotionally available and less sensitive to the needs of their children. The negative interactions "spill over" into the parent/child relationship, resulting in an increase in negative parenting practices, such as poor monitoring, inconsistency, and harsh discipline. In contrast, constructive marital conflict, such as satisfaction, support, and positive interaction, spills over into the parent/child relationship, which is characterized by increased availability to meet children's needs, and results in more positive parenting practices, such as involvement and praise. Moreover, several studies examining the effects of conflict on children's emotional and behavioral outcomes, have also demonstrated ways of categorizing conflict into destructive and constructive marital conflict [84-88]. These studies suggest that destructive marital conflict make children more vulnerable to developing adjustment problems including aggression, conduct disorders, anxiety, and depressive symptomatology.
Conversely, these studies also suggest that constructive marital conflict, including progress towards the resolution of the conflicts and explanations about how conflicts were resolved, is likely to be beneficial to children, helping them learn effective problem-solving and communication skills. Therefore, the findings illustrate the need to examine marital conflict as a multidimensional construct to understand how conflict affects children.

However, despite the extensive research completed in this area, studies have minimally considered the impact of positive dimensions of marital conflict and in turn, parenting practices (positive spillover), rather than negative dimensions (negative spillover), as mediators in the link between SES and child mental health functioning. Previous studies have consistently found that destructive marital conflict fosters negative spillover, resulting in more negative parent/child interactions [18]. Furthermore, a limitation of previous empirical work is that studies have focused exclusively on negative outcomes (e.g., internalizing and externalizing behavioral problems) $[17,18]$. Further studies examining a positive association between family factors and child mental health functioning, including positive outcomes, have been called for. Therefore, investigations into positive spillover practices (i.e., constructive marital conflict, positive parenting practices, and positive child outcomes) are needed to clarify how family functioning affects child development in a comprehensive model.

\section{Social competence and child adjustment}

School maladjustment is one of the most prevalent and significant health problems threatening children. Previous studies have suggested that one of the factors related to child maladjustment is a child's inability to adjust socially, as a result of a lack of social competence [89]. Social competence has been broadly defined as effectiveness in social interactions [20]. Social skills are discrete abilities that contribute to social competence [19]. Specifically, these skills have been defined as socially acceptable learned behaviors that enable children to interact effectively and avoid unacceptable responses from others [90]. In short, social competence refers to an individual's overall ability to act in a socially appropriate manner [19], whereas social skills refer to specific and distinct behaviors representing social competence [91].

Social skills are some of the most important accomplishments in childhood. Aspects of social skills, such as cooperation, self-control, and assertion, which were clustered by Gresham and Elliott [90], affect social adaptation in later life. Social skills help children initiate positive peer interactions, which help them learn positive behaviors through peer modeling and provide them with resources, such as support and acceptance [92-95]. 
Conversely, children who fail to develop social skills in early developmental phases often display social problems. Children who persistently exhibit deficits in social skills experience both short- and long-term negative consequences, which may often be precursors to more severe social problems later in life [96, 97]. Children who lack social skills may experience emotional difficulties, and tend to have trouble interacting with their peers, teachers, and families [97-100]. Furthermore, social skill deficits frequently demonstrate a negative association with behavioral adjustment [99-102].

Behavioral adjustment is generally associated with two broad symptom dimensions: internalizing and externalizing behaviors. Internalizing behaviors include worry, anxiety, depression, and somatic complaints; while externalizing behaviors include hyperactivity, inattention, aggression toward peers, and management problems [103-110]. Internalizing and externalizing behaviors consistently influence each other over time, with prior studies showing that internalizing behaviors predict later externalizing behaviors, and vice versa [111-116]. Further, there is evidence of co-morbidity with internalizing and externalizing behaviors later in the life course.

Social competence predicts internalizing and externalizing behaviors across longer periods in childhood, adolescence, and adulthood. Additionally, lower social competence forecasts higher levels of both internalizing and externalizing problems [99-102, 117, 118]. Children who lack social skills have difficulties in expressing themselves and understanding others, such as sending appropriate social messages and responding to their peers, teachers, and families. They have fewer positive interactions and have more trouble interacting with others. Consequently, these individuals are more prone to be disliked and deemed socially incompetent by others [119]. Therefore, children with social skill deficits are at an elevated risk for social isolation, including anxious solitude and peer rejection.

Social isolation is associated with behavioral adjustment. For instance, increased childhood social isolation longitudinally predicts depressive symptoms [120-122]. Therefore, early peer difficulties with social skill deficits are predictive of later maladjustment. The cross-sectional and longitudinal associations between social competence deficits and internalizing symptoms have been well documented from preschool to adolescence [123-125]. Similarly, several studies suggest childhood peer rejection longitudinally predicts externalizing behaviors, including aggression, conduct disorders involving peers, and other under-controlled behaviors during the school-age years and into adolescence [101, 102, 126]. However, several social skill abilities among children that are associated with externalizing behaviors, such as abilities in emotion regulation, verbally expressing emotions, and self-regulation of behavior, generally increase with age $[127,128]$. Therefore, as social skills improve with age, the rates of externalizing problems tend to decrease in comparison to internalizing problems [127-129]. Eventually, the failure to develop social skills and successful childhood interpersonal relationships could promote mental health difficulties and both internalizing and externalizing problems over time.

Early childhood is a pivotal period for social development. The transition period from early childhood to elementary school first grade is a pivotal period for social development that leads to school readiness. Previous research has indicated that the preschool years are a sensitive period for the acquisition of social skills and related abilities [130-135]. Preschool-aged children learn and frequently display various prosocial behaviors [136]. Therefore, this period is an important developmental stage during when children are expected to acquire social skills to prepare them for broader social activity. Social skill deficits in early childhood gradually become permanent over time, are related to poor academic performance, and are predictive of social adjustment problems and serious psychopathology in adolescence. Understanding the factors that influence these developmental processes in early childhood may enable the prevention of later socio-emotional difficulties.

There is an extensive body of literature demonstrating that the development of social competence among children is significantly affected by environmental factors in childhood [137-139]. For example, family functioning (e.g., the inter-parental relationship, parent/ child interactions) has been shown to predict children's social competence. Positive parenting, such as emotional expressiveness, responsiveness, and support, has been shown to enhance empathy and social functioning in children [140-143], while negative parenting behavior, such as harsh discipline, emotional neglect, or rejecting behavior, is often associated with lower sociability/ social competence and increased problem behaviors in children $[16,25,143]$.

Many previous studies have also shown that destructive marital conflicts negatively affect social competence [144]. This type of marital conflict may put children at risk of developing adjustment problems, including internalizing and externalizing disorders, due to their inability to control their emotions. Moreover, they may learn through these interactions to solve problems through aggressive behavior [18, 145-147]. Since research has primarily focused on destructive marital conflict, few studies have investigated constructive marital conflict, which may foster social competence. Constructive marital conflict may also aid in the development of problem-solving, 
coping, and conflict resolution abilities by teaching children how to effectively communicate with others to solve issues [148-150]. Previous studies consistently suggest that destructive conflict increases the risk of adjustment disorders, whereas constructive conflict may positively influence adjustment. Despite the differential effects of destructive and constructive conflict on child development, there is no distinction between these two types of conflict and their implications for social development within the literature. Moreover, even though marital conflict and parenting practices affect social competence $[144,151]$, few studies have addressed the various ways that this may occur within a comprehensive model.

As mentioned previously, a limitation of empirical work on the FSM is that studies have focused exclusively on negative outcomes, such as internalizing and externalizing problems $[7,15]$. This myopic focus leads to a strong need for the examination of positive associations, such as positive developmental outcomes among children (e.g., social competence). The current study highlights the ways that family processes within the FSM promote desirable child outcomes, specifically focusing on the development of social competence.

Various studies have demonstrated the significant effects of family processes on social competence, primarily examining the individual relationships between different types of SES, marital conflict, parenting practices, and child mental health functioning, without considering associations in a comprehensive model. When considering the complex relationships among these variables, it is also important to consider independent associations, while controlling for other variables. For a more detailed exploration of the early protective factors potentially influencing diverse developmental maladjustment, the purpose of this preliminary study was to examine, in greater detail, social competence as a mediator of the relationships between SES, family processes, and children's adjustment.

\section{Present study}

Although several studies have demonstrated a significant impact of SES and family processes (i.e., marital conflict and parenting practices) on general adjustment among children, few have considered the relationship between child behavioral problems and SES, including family economic and parental educational levels, negative and positive aspects of marital conflict and parenting practices, and child social competence, in conjunction with one another. Most prior studies including the FSM have focused little attention on the educational domain of SES or the positive aspects of family functioning and child outcomes. When considering the complex relationships between these variables, it is important to consider independent associations, while controlling for other variables in a comprehensive model. Most studies have examined these complex relationships in a more piecemeal fashion, rarely integrating them into a unified conceptual model. Within the risk and resilience research framework, relational risk or protective factors are thought to make either additive or contingent contributions to adjustment.

Based on the observations above, the aim of this study was to clarify the roles of SES (i.e., family income and maternal and paternal educational levels), marital conflict (i.e., destructive and constructive marital conflict), parenting practices (i.e., negative and positive parenting practices), and child social competence (i.e., social skills) and behavioral problems (i.e. internalizing and externalizing problems), by analyzing these relationships in a comprehensive model. In the present study, we used longitudinal assessments of children's externalizing and internalizing behaviors to evaluate the hypothesis that SES, marital conflict, and parenting practices predict children's social competence, which is then related to later child adjustment. The mediational model in Fig. 1 was tested to estimate the direct effects of Time 1 (T1; participants were 5 years old, in preschool) SES, marital conflict, and parenting practices on Time 2 (T2; participants were 6 years old, in the first grade) behavioral problems, and to examine the indirect effects of $\mathrm{T} 1$ variables, through their effects on $\mathrm{T} 1$ social competence, on $\mathrm{T} 2$ behavioral problems. As a result, our study provides theoretical contributions to the FSM by incorporating additional critical factors (i.e., parental educational levels, positive aspects of family functioning, and positive child outcomes). Investigating the role of social competence as a mediating process in the link between relational risks such as SES and later child adjustment will enable important theoretical contributions to the understanding of processes involved in the development of adaptation among children with higher relational risks, and will provide implications for prevention and intervention efforts.

We hypothesized the following pathways: (1) SES indicators (i.e., family income and maternal and paternal educational levels) are, as predictors, differentially associated with family processes (i.e., marital conflict and parenting practices) and child mental functioning (i.e., social competence and adjustment) through distinct pathways; (2) both negative and positive aspects of family processes will mediate the relationship between SES and child mental health functioning; and (3) social competence in preschool, which is influenced by multidimensional family factors, will reduce the risk of behavioral problems in the first grade. 


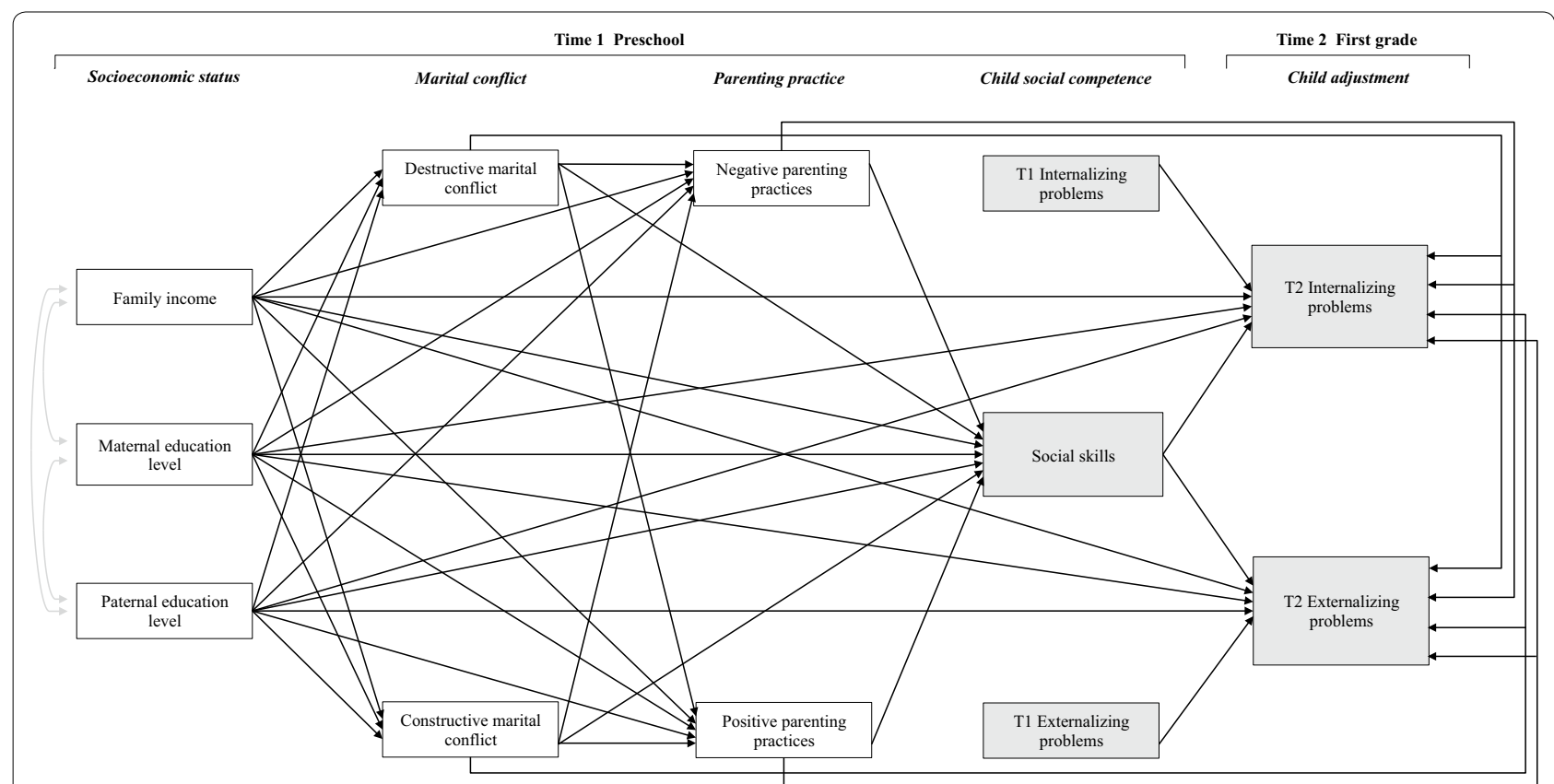

Fig. 1 Hypothesized model. This model includes the hypothesized pathways among socioeconomic status, marital conflict, parenting practices, and children's mental health functioning

\section{Methods}

\section{Participants}

The current investigation consisted of two waves of data, taken 1 year apart, and was part of a longitudinal study that examined the influence of family factors on child social developmental outcomes. Figure 2 illustrates the

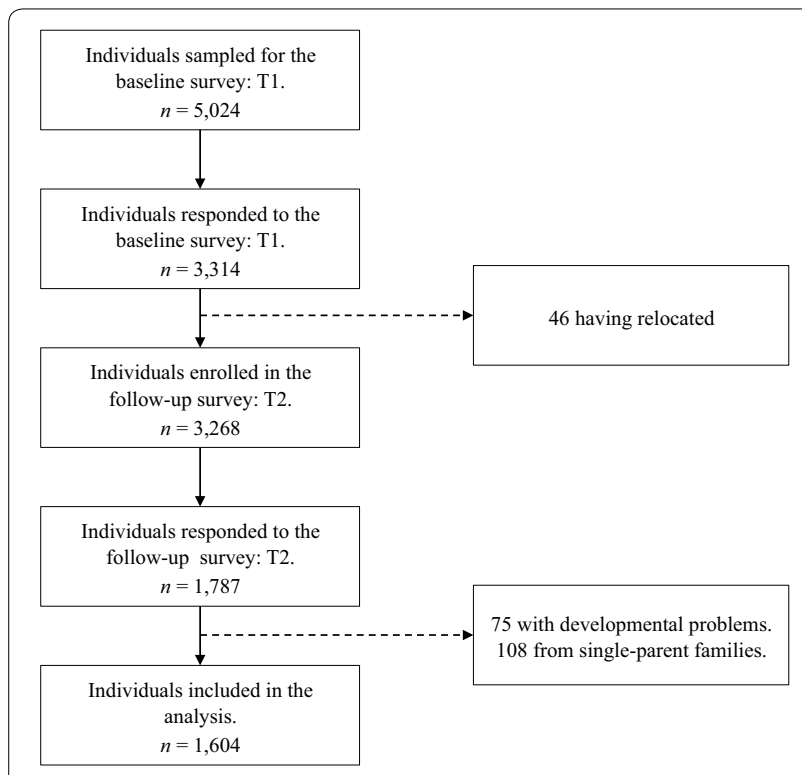

Fig. 2 Flow chart of the study participants of the study flow chart of participants for this study. At T1 in 2014, participants were 5 years old and in preschool. Selfreported questionnaires were provided to the parents of children $(n=5024)$ enrolled in 52 kindergartens and 78 nursery schools in Nagoya city, which is a major urban area in Japan. A total of 3314 parents completed the questionnaires. At T2 in 2015, participants were 6 years old and in the first grade. Parents returned 1 year (12 months) after T1 to participate in the second wave of data collection. The retention rate from $\mathrm{T} 1$ to $\mathrm{T} 2$ was $53.9 \%$, resulting in an ultimate sample size of 1787 for the current study.

In the present paper, to clarify the associations between SES accurately, including parents' educational levels, marital relationship, parenting practices, and child developmental outcomes, the following individuals were excluded from analyses: (1) children from single-parent families, (2) children diagnosed with developmental problems, and (3) children whose mothers did not return completed questionnaires. For inclusion in this study, parents did not have to be the target child's biological parent; however, they did need to reside with the child. For both $\mathrm{T} 1$ and $\mathrm{T} 2$, of the 1787 children, 1604 (89.8\%) met the inclusion criteria. The children's data, as provided by the mothers, were analyzed in this study.

At T1, mean age was 6.09 years $(S D=.30)$, with $51.5 \%$ of the sample being males $(n=826)$ and $48.5 \%$ being females $(n=778)$. In total, $48.5 \%$ of the sample were 
children attending kindergarten $(n=778)$, and $51.5 \%$ were children attending nursery schools $(n=826)$. The mean ages of the mothers and fathers were 37.41 $(S D=4.47)$ and $39.33(S D=5.44)$ years, respectively. SES indicators (i.e., family income and parental education level) are shown in Table 1 . The median household income was between $\Varangle 5,000,000$ and $\Varangle 5,999,999$ per year (approximately \$ 50,000 and \$ 59,999 USD per year). On average, mothers and fathers had completed comparable years of education, at 14.13 years $(S D=1.75)$ and 14.56 years $(S D=2.25)$, respectively.

We compared the T2 non-returning participants with the T2 returning participants on demographic features (i.e., parental age, family income, and parental education level). The mean ages of T2 non-returning participant mothers and fathers were $36.79(S D=4.82)$ and 38.92 $(S D=5.86)$ years, respectively. The T2 non-returning participants were comparatively younger parents that returned at T2, according to independent samples $t$ tests $(p<.05)$. A Chi square test yielded a significant $(p<.001)$ difference between household incomes, with $24.8 \%$ of the T2 non-returning participants reporting below Y 3,999,999 per year, while only $17.7 \%$ of T2 returning participants reported this level. On average, the T2 non-returning participants' mothers and fathers had comparable years of completed education, at 13.72 years $(S D=1.87)$ and 14.01 years $(S D=2.42)$, respectively.

Table 1 Parent and family characteristics of the study sample in percentages $(n=1604)$

\begin{tabular}{lrr}
\hline Description & $\mathbf{n}$ & $\%$ \\
\hline Annual household income (in millions of yen) & & \\
$<4$ & 284 & 17.7 \\
$4-5$ & 536 & 33.4 \\
$6-7$ & 368 & 22.9 \\
$8-9$ & 185 & 11.5 \\
$10-11$ & 107 & 6.7 \\
$\geq 12$ & 86 & 5.4 \\
No response & 38 & 2.4 \\
Maternal education level & & \\
Compulsory education (9 years) & 35 & 2.2 \\
Upper secondary school (12 years) & 370 & 23.1 \\
Less than 4 years at college/university (13-15 years) & 661 & 41.2 \\
Over 4 years at college/university ( $\geq 16$ years) & 529 & 33.0 \\
No response & 9 & .6 \\
Paternal education level & & \\
Compulsory education (9 years) & 77 & 4.8 \\
Upper secondary school (12 years) & 382 & 23.8 \\
Less than 4 years at college/university (13-15 years) & 239 & 14.9 \\
Over 4 years at college/university ( $\geq 16$ years) & 895 & 55.8 \\
No response & 11 & .7 \\
\hline
\end{tabular}

Additionally, a $t$-test revealed that the education level of non-returning participants was significantly lower $(p<.001)$ than the education level of individuals that did return. Thus, the non-returning participants tended to have relatively lower SES than did returning participants, meaning that there was a lower response rate of individuals with low SES compared to high SES.

\section{Ethics statement}

The children's parents and teachers were informed of the study's purpose and procedures, and they were made aware that they were not obligated to participate. The teachers provided their written informed consent, and the parents submitted the same on behalf of their children prior to participating in this research. Ethical approval for this study was obtained from Kyoto University's Ethics Committee in Kyoto, Japan (E2322).

\section{Measures}

All the questions used for the self-developed questionnaire were questions translated into Japanese.

\section{Predictors}

Socioeconomic status At T1, SES was defined as information about family income levels, as provided by the parents, and parental education. Parents were asked to report their total yearly family income, their education in years, and their completed education levels by choosing one of the following response options: compulsory education (9 years), vocational upper-secondary school/general upper-secondary school (12 years), less than 4 years at college/university (13-15 years; i.e., junior college, vocational school, or professional school), and over 4 years at college/university ( $\geq 16$ years). Each of the SES scores (i.e., yearly family income and years of parental education) were converted to $z$ scores.

\section{Mediators}

Marital conflict At T1, the Quality of Co-parental Communication Scale (QCCS), a 10-item self-report questionnaire, was used to assess each parent's feelings or behaviors within the context of the co-parenting relationship [120]. This measure is composed of the following two subscales: Co-parental Conflict (four items relating to conflict, hostility, tension, and disagreements) and Co-parental Support (six items relating to accommodation, helpfulness, and resourcefulness). Items are rated on a 5-point Likert scale ranging from 1 (Never) to 5 (Always). The Conflict and Support subscales assess parents' perceptions of the co-parenting relationship. The Conflict subscale measures the negative aspect of the co-parenting relationship, with higher conflict scores indicating more co-parental communication conflict [152]. In the current study, we con- 
sidered Co-parental Conflict as destructive conflict. Conversely, the Support subscale measures positive aspects of the co-parenting relationship, with higher support scores indicating more supportive co-parental communication [152]. Specifically, the Support subscale measures "general support" including helpfulness, resourcefulness, and cooperation [152], as opposed to the constructive aspects of conflict. However, in the current study, we considered Co-parental Support as constructive marital conflict. The scales have adequate internal consistency and construct validity [152-154]. The internal consistency was .88 and .74 for Conflict and Support scales, respectively [152]. The current study found internal consistencies of .77 and .86 for the Conflict and Support scales, respectively. Each QCCS total score was converted to a $z$ score.

Parenting practice At T1, the Alabama Parenting Questionnaire (APQ), a 42-item self-report questionnaire, was used to assess various aspects of parenting behavior $[155,156]$. The measure is composed of the following five subscales: Poor Monitoring/Supervision, Inconsistent Discipline, Corporal Punishment, Positive Parenting, and Involvement. Items are rated on a 5-point Likert scale ranging from 1 (Never) to 5 (Always). Participants self-reported their own parenting behavior. The developers have reported that the measure has adequate internal consistency and construct validity [156]. The internal consistency of the subscales ranges from .46 to .80 [156]. In this study, the subscales' internal consistency ranged from .71 to .76 .

In this study, we standardized the separate positive and negative parenting composite scores [157]. Scores on the Poor Monitoring/Supervision, Inconsistent Discipline, and Corporal Punishment subscales of the APQ were combined to form a negative parenting composite score, whereas scores on the Positive Parenting and Involvement subscales were combined to form a Positive Parenting composite score. The Negative Parenting composite score was calculated by converting the Poor Monitoring/ Supervision, Inconsistent Discipline, and Corporal Punishment subscale scores to $z$ scores and then averaging them, with higher scores indicating more negative parenting. Similarly, the Positive Parenting composite score was calculated using the same method for the Positive Parenting and Involvement subscale scores, with higher scores indicating more positive parenting.

Child social competence At T1, the Social Skills Questionnaire (SSQ) was used as an index of observer ratings of child social competence. In the current study, the children's teachers evaluated their social skills using this scale. The SSQ is a 24-item measure of children's social competence in relation to "cooperation", "self-control", and "assertion" [158-160], as factors affecting social adaptation in later life [90]. These clusters of social behaviors can briefly be characterized as follows: Cooperationbehaviors such as helping others, sharing with a peer, and complying with rules such as sharing and obeying; Self-control-behaviors that emerge in conflict situations, such as responding appropriately to (i.e., controlling one's temper) teasing or corrective feedback from an adult; and Assertion-behaviors such as asking others for help/information and responding to others' actions (e.g., responses to peer pressure).

The SSQ has the following three subscales: Cooperation (eight items; e.g., the child helps someone voluntarily), Self-control (eight items; e.g., the child behaves if there is a need), and Assertion (eight items; e.g., the child initiates a conversation with someone). These factors are based upon, and positively correlated with, the Social Skills Rating System (SSRS) [90], which is one of the most widely used social skills scales and was used in the National Institute of Child Health and Human Development (NICHD) study $[161,162]$. The SSQ's items are rated on a 3-point scale ranging from 0 (Not at all) to 2 (Often), yielding total scores for cooperation, self-control, and assertiveness. The SSQ has adequate internal consistency and construct validity; the subscales' internal consistency has previously ranged from .91 to .93 [158], with a range from .84 to 94 in the current study. Furthermore, the present study combined total scores for cooperation, self-control, and assertiveness to form a social skills score, with higher scores indicating better social skills. The social skills score was calculated by converting scores on the Cooperation, Self-control, and Assertion subscales to $z$ scores, and then averaging them.

\section{Criterion variables}

Child adjustment The Strengths and Difficulties Questionnaire (SDQ) is a 25-item measure of parents' perceptions of their children's prosocial and difficult behaviors, and it is designed to assess general internalizing and externalizing emotional and behavioral problems [163]. In this study, children's mothers evaluated their behavioral adjustment using this scale at both $\mathrm{T} 1$ and $\mathrm{T} 2$. The measure is composed of the following five subscales: Emotional Symptoms, Conduct Problems, Hyperactivity-Inattention, Peer Problems, and Prosocial Behavior. Items were rated on a 3-point Likert scale ranging from 0 (Not true) to 2 (Certainly true). The scales' internal consistency and construct validity were reported as adequate [164-166].

In this study, the Emotional Symptoms and Peer Problems subscales of the SDQ were combined to form an Internalizing Problems scale (Cronbach's $\alpha=.65, .71$ ), while the Conduct Problems and Hyperactivity-Inattention subscales were combined to form an Externalizing 
Problem scale (Cronbach's $\alpha=.74, .77$ ), as suggested by Goodman et al. [167], with higher scores indicating more behavioral problems. Each SDQ total score was converted to a $z$ score.

\section{Procedure}

To conduct our study, we asked the kindergartens and nursery schools with 50 or more students, in Nagoya city, to participate. As a result, principals of 130 facilities (52 kindergartens and 78 nursery schools) gave us permission to conduct our survey and meet with participating parents. To recruit families at T1, self-reported questionnaires were distributed at the participating facilities to all parents of 5 year olds $(n=5024)$. Participants received an information sheet and questionnaires on childrearing, in relation to family factors (i.e., SES, family relationships, and parenting style), and child behavioral adjustment (i.e., externalizing and internalizing problems). Participants provided written informed consent and agreed to participate. The parents completed the questionnaires at a single time point and returned these to participating facilities in sealed envelopes to prevent teachers from seeing the questionnaires. Then, the teachers evaluated the children's social skills using the SSQ. All sealed envelopes containing questionnaires and SSQ evaluations were returned to the researcher from the respective principals.

At T2, 12 months later, participants were contacted again when the children were in the first grade. At $\mathrm{T} 1$, the researcher obtained the address of participants, and, at $\mathrm{T} 2$, the researcher mailed the participants questionnaires on childrearing in relation to family factors and child behavioral adjustment. Participants who completed the questionnaires returned them to the researcher by mail. Access to the data was restricted to the researchers of the current longitudinal study.

\section{Data analyses}

First, prior to developing a model of the relationships among SES, parental relationship, parenting practices, and child social competence and adjustment, correlation analyses were utilized to determine the associations among SES (i.e., T1 family income, maternal and paternal levels of education), marital relationship (i.e., T1 destructive and constructive marital conflict), parenting practices (i.e., $\mathrm{T} 1$ negative and positive parenting practices), child social competence (i.e., T1 social skills), and child adjustment (i.e., T1 and T2 internalizing and externalizing problems).

Second, path analyses were conducted to estimate direct and indirect paths between SES, parental relationship, parenting practices, and child social competence and adjustment. Structural equation modeling analyses were conducted using full information maximum-likelihood estimation in the presence of missing data. The hypothesized model is presented in Fig. 1. In the models, SES (i.e., T1 family income and parental level of education) was specified as a predictor of the marital relationship (i.e., T1 destructive and constructive marital conflict), parenting practices (i.e., T1 negative and positive parenting practices), child social competence (i.e., T1 social skills), and behavioral adjustment (i.e., T1 and T2 externalizing and internalizing problems). We estimated how family factors (i.e., SES, marital conflict, and parenting) and child social competence in preschool influenced the children's behavioral adjustment in the first grade. The model also included T1 behavioral adjustment as control variables; through controlling for initial levels of maladjustment, the model would appropriately address changes in behavioral adjustment. Based on previous findings in the literature, we expected the effect of T1 SES indicators on $\mathrm{T} 2$ behavioral adjustment to be mediated by the $\mathrm{T} 1$ parental relationship, parenting practices, and social competence. Moreover, we expected an inverse effect between $\mathrm{T} 1$ social competence and $\mathrm{T} 2$ adjustment.

To assess fit, we examined the Comparative Fit Index (CFI) [168], the Incremental Fit Index (IFI) [169], and the Root Mean Square Error of Approximation (RMSEA) [170]. Good model fit is reflected in CFI and IFI values above $90[168,169]$. Regarding the RMSEA, good fit was represented by a value smaller than .05 and reasonable fit was represented by values ranging from .05 to .08 [171]. All the statistical analyses were conducted using SPSS version 23.0 and Amos version 23.0.

\section{Results}

\section{Preliminary analyses}

SES indicators are shown in Table 1. Other descriptive statistics for all variables measured by the scales (i.e., marital conflict, parenting practices, child social competence, and behavioral adjustment) are presented in Table 2. A correlation matrix of the SES indicators, marital conflict, parenting practices, and child social competence and behavioral adjustment is shown in Table 3 . Analyses in study composites showed that all correlations of the study composites were statistically significant. The indicators of SES, marital conflict, parenting practice, and child social competence and behavioral adjustment were interrelated, supporting our hypotheses and previous empirical findings. Each SES variable (i.e., family income and maternal and paternal educational levels) was negatively related to destructive marital conflict, negative parenting, and the children's externalizing and internalizing behavioral problems. Conversely, it was positively related to constructive marital conflict, positive parenting, and children's social skills. In turn, social skills inversely 
Table 2 Descriptive statistics for the study variables $(n=1604)$

\begin{tabular}{lcccc}
\hline Description & Range & M & SD & Cronbach's a \\
\hline Marital conflict: Quality of Co-Parental Communication Scale (QCCS) \\
Co-parental Conflict & $4-20$ & 9.88 & 3.01 & .77 \\
Co-parental Support & $6-30$ & 25.16 & 4.14 & .86 \\
Parenting practice: Alabama Parenting Questionnaire (APQ) \\
Poor monitoring/supervision & $10-50$ & 12.87 & 2.94 & .71 \\
Inconsistent discipline & $6-30$ & 14.53 & 3.77 & .73 \\
Corporal punishment & $3-15$ & 7.06 & 2.17 & .72 \\
Positive parenting & $6-30$ & 22.35 & 3.49 & .76 \\
Involvement & $10-50$ & 37.99 & 5.07 & .75 \\
Social competence: Social Skills Questionnaire (SSQ) & \\
Cooperation & $0-16$ & 10.97 & 4.13 & .94 \\
Self-control & $0-16$ & 14.18 & 2.64 & .90 \\
Assertion & $0-16$ & 14.08 & 2.37 & .84 \\
Child adjustment: Strengths and Difficulties Questionnaire (SDQ) \\
T1 internalizing problems & $0-20$ & 3.34 & 2.70 & .65 \\
T1 externalizing problems & $0-20$ & 5.02 & 3.21 & .74 \\
T2 internalizing problems & $0-20$ & 3.88 & 3.04 & .71 \\
T2 externalizing problems & $0-20$ & 5.15 & 3.29 & .77 \\
\hline
\end{tabular}

T1: Time 1, preschool; T2: Time 2, first grade

correlated with children's externalizing and internalizing behavioral problems.

\section{Mediational models for SES, marital conflict, parenting practices, child social skills, and child adjustment}

Longitudinal models examined the impact of SES, marital conflict, and parenting practices on child social competence and behavioral adjustment (Hypothesized model; Fig. 1). Figure 3 depicts the final path models, and the path diagram specifies both direct and indirect paths linking T1 SES indicators (i.e., family income and maternal and paternal educational levels) to T2 child behavioral adjustment (i.e., externalizing and internalizing problems; Table 4).

The standardized coefficients are shown in Fig. 3. Model fit was tested with multiple indices; the model provided a good fit to the data $\left[\chi^{2}(18)=31.89, p=.023\right.$; $\mathrm{CFI}=.99 ; \mathrm{IFI}=.99 ; \mathrm{RMSEA}=.02]$.

In the model, several statistically significant direct and indirect paths were found between the predictors and criterion variables. Family income was found to be a significant predictor of lower levels of destructive marital conflict $(\beta=-.11, p<.001)$, lower levels of negative parenting practices $(\beta=-.11, p<.001)$, higher levels of constructive marital conflict $(\beta=.09, p<.01)$, higher levels of positive parenting practices $(\beta=.09, p<.01)$, higher levels of child social skills $(\beta=.09, p<.01)$, and lower levels of T2 internalizing problems $(\beta=-.08$, $p<.001)$ and T2 externalizing problems $(\beta=-.06$, $p<.01)$. The indirect paths from family economy to child mental health functioning (i.e., social skills and internalizing and externalizing problems) through marital conflict and parenting practices were also significant.

Maternal education level was found to be a significant predictor of lower levels of negative parenting practices $(\beta=-.07, p<.05)$, higher levels of constructive marital conflict $(\beta=.07, p<.05)$, higher levels of positive parenting practices $(\beta=.06, p<.05)$, and lower levels of T2 internalizing problems $(\beta=-.09, p<.001)$ and $\mathrm{T} 2$ externalizing problems $(\beta=-.05, p<.05)$. The indirect paths from maternal education level to child mental health functioning (i.e., social skills and internalizing and externalizing problems) through marital conflict and parenting practices were also significant.

Paternal education level was found to be a significant predictor of lower levels of destructive marital conflict $(\beta=-.10, p<.001)$, lower levels of negative parenting practices $(\beta=-.06, p<.05)$, higher levels of constructive marital conflict $(\beta=.10, p<.001)$, and higher levels of child social skills $(\beta=.08, p<.01)$. The indirect paths from paternal education level to child mental health functioning (i.e., social skills and internalizing and externalizing problems) through marital conflict and parenting practices were also significant.

Notably, in terms of the negative dimension of family processes (marital conflicts and parenting practices), T1 destructive conflict was directly, negatively related to social skills $(\beta=-.11, p<.001)$, and indirectly, negatively related to $\mathrm{T} 1$ social skills through $\mathrm{T} 1$ negative parenting practices. T1 negative parenting practices were directly, negatively related to social skills $(\beta=-.10$, $p<.001)$. Regarding the positive dimension of family processes, T1 constructive conflict was directly, positively related to social skills $(\beta=.09, p<.01)$, and indirectly, positively related to $\mathrm{T} 1$ social skills through $\mathrm{T} 1$ positive parenting practices. T1 positive parenting practices were directly, positively related to social skills $(\beta=.08$, $p<.01)$. In turn, T1 social skills were found to be a direct and significant predictor of lower levels of T2 internalizing problems $(\beta=-.38, p<.001)$ and T2 externalizing problems $(\beta=-.45, p<.001)$, while controlling for behavior problems at $\mathrm{T} 1$.

Therefore, consistent with the hypotheses, each SES indicator was significantly and independently associated with child mental health functioning (i.e., social skills and internalizing/externalizing problems) through positive and negative dimensions of marital conflict and parenting practices. Notably, T1 social skills in preschool, which were affected by $\mathrm{T} 1$ family factors, predicted lower levels of $\mathrm{T} 2$ behavioral problems in the first grade. 


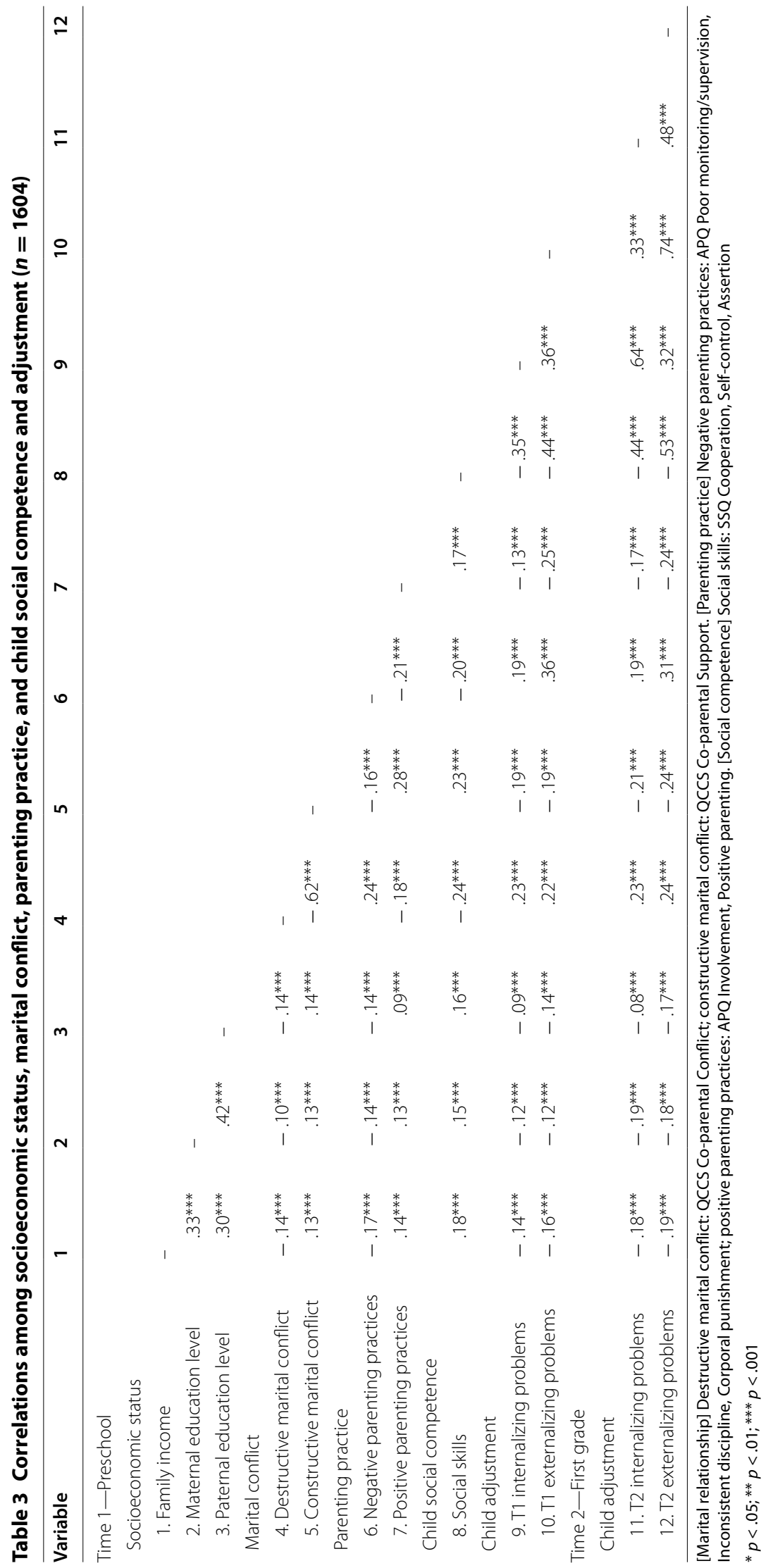




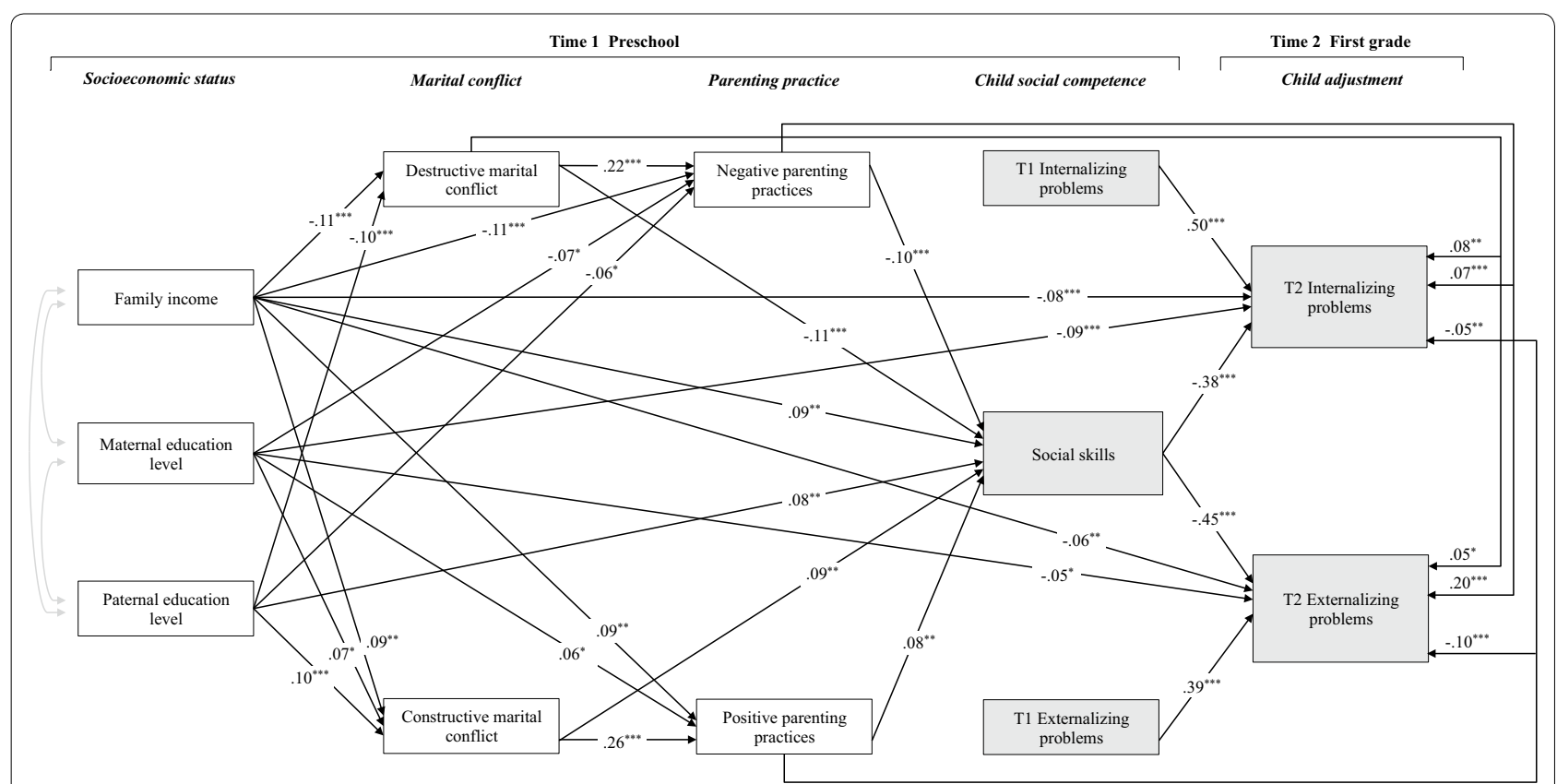

Fig. 3 Statistically significant paths. This model includes the paths that were statistically significant in the hypothesized model. Model fit statistics: $X^{2}(18)=31.89 ; \mathrm{CFI}=.99 ; \mathrm{IFI}=.99 ; \mathrm{RMSEA}=.02 .{ }^{*} p<.05 ;{ }^{* *} p<.01 ;{ }^{* * *} p<.001$

\section{Discussion}

Our longitudinal study explored, in a comprehensive model, marital conflict (i.e., constructive and destructive marital conflict), parenting practices (i.e., positive and negative parenting practices), and social competence (i.e., social skills) as mediators of the association between SES (i.e., family income, maternal and paternal educational levels) in preschool and child behavioral adjustment (i.e., internalizing and externalizing problems) in the first grade. Our extension of previous research investigating the relationships between SES and child behavioral adjustment comprised the following three points. (1) We included both family income, and maternal and paternal education levels as SES indicators, and as predictors of family processes (i.e., marital conflict and parenting practice) and mental health functioning of children (i.e., social competence and behavioral adjustment), in a unified model. We expected each SES indicator, as predictors, to be differentially associated with family processes and child mental functioning through distinct pathways. (2) We included not only negative mediators (i.e., destructive marital conflict and negative parenting practices), but also positive mediators (i.e., constructive marital conflict and positive parenting), as mediating mechanisms in the link between SES and child mental health functioning. We expected both negative pathways (negative spillover) and positive pathways (positive spillover) in the family process model. (3) We included not only negative child developmental outcomes (i.e., behavioral problems), but also desirable child developmental outcomes (i.e., social competence) in the relationship between family factors (i.e., SES and family processes) and child mental health functioning. Moreover, we focused on social competence as a mediator of the relationship between family factors and child behavioral problems. We expected social competence in preschool, which was affected by different types of family factors, to be inversely related to the symptoms of behavioral problems in the first grade.

Our main findings were the following. (1) Family income and parental education levels were differentially associated with child mental health functioning through distinct pathways. This result provides evidence that lower SES (i.e., lower family income and lower parental education level) is both directly and indirectly associated with more destructive marital conflict, more use of negative parenting practices, less constructive marital conflict, less use of positive parenting practices, poorer social competence, and more symptoms of behavioral problems. This suggests that, by contrast, higher SES (higher family economy and higher parental education levels) is both directly and indirectly associated with less destructive marital conflict, less use of negative parenting practices, more constructive marital conflict, more use of positive parenting practices, higher social competence, and fewer symptoms of behavioral problems. (2) We identified both negative and positive pathways between SES and child mental health functioning. Positive mediators included constructive marital conflict and positive 
Table 4 Path analyses $(n=1604)$

\begin{tabular}{|c|c|c|c|c|c|}
\hline Construct & & & B & SE & $\beta$ \\
\hline \multicolumn{6}{|l|}{ Socioeconomic status } \\
\hline Family income & $\rightarrow$ & Destructive marital conflict & -.11 & .03 & $-3.83^{* * *}$ \\
\hline Family income & $\rightarrow$ & Constructive marital conflict & .09 & .03 & $3.04^{* *}$ \\
\hline Family income & $\rightarrow$ & Negative parenting practices & -.11 & .03 & $-3.82^{* * *}$ \\
\hline Family income & $\rightarrow$ & Positive parenting practices & .09 & .03 & $3.05^{* *}$ \\
\hline Family income & $\rightarrow$ & Social skills & .09 & .03 & $3.29^{* *}$ \\
\hline Family income & $\rightarrow$ & T2 internalizing problems & -.08 & .02 & $-3.48^{* * *}$ \\
\hline Family income & $\rightarrow$ & T2 externalizing problems & -.06 & .02 & $-2.65^{* *}$ \\
\hline Maternal education level & $\rightarrow$ & Destructive marital conflict & -.03 & .03 & -.90 \\
\hline Maternal education level & $\rightarrow$ & Constructive marital conflict & .07 & .03 & $2.17^{*}$ \\
\hline Maternal education level & $\rightarrow$ & Negative parenting practices & -.07 & .03 & $-2.28^{*}$ \\
\hline Maternal education level & $\rightarrow$ & Positive parenting practices & .06 & .03 & $2.03^{*}$ \\
\hline Maternal education level & $\rightarrow$ & Social skills & .04 & .03 & 1.18 \\
\hline Maternal education level & $\rightarrow$ & T2 internalizing problems & -.09 & .02 & $-3.75^{* * *}$ \\
\hline Maternal education level & $\rightarrow$ & T2 externalizing problems & -.05 & .02 & $-2.11^{*}$ \\
\hline Paternal education level & $\rightarrow$ & Destructive marital conflict & -.10 & .03 & $-3.46^{* * *}$ \\
\hline Paternal education level & $\rightarrow$ & Constructive marital conflict & .10 & .03 & $3.31^{* * *}$ \\
\hline Paternal education level & $\rightarrow$ & Negative parenting practices & -.06 & .03 & $-2.08^{*}$ \\
\hline Paternal education level & $\rightarrow$ & Positive parenting practices & .01 & .03 & .38 \\
\hline Paternal education level & $\rightarrow$ & Social skills & .08 & .03 & $2.85^{* *}$ \\
\hline Paternal education level & $\rightarrow$ & T2 internalizing problems & -.04 & .02 & -1.69 \\
\hline Paternal education level & $\rightarrow$ & T2 externalizing problems & -.02 & .02 & -.67 \\
\hline \multicolumn{6}{|l|}{ Marital conflict } \\
\hline Destructive marital conflict & $\rightarrow$ & Negative parenting practices & .22 & .03 & $6.83^{* * *}$ \\
\hline Destructive marital conflict & $\rightarrow$ & Positive parenting practices & -.01 & .03 & -.30 \\
\hline Destructive marital conflict & $\rightarrow$ & Social skills & -.11 & .03 & $-3.47^{* * *}$ \\
\hline Destructive marital conflict & $\rightarrow$ & T2 internalizing problems & .08 & .03 & $3.08^{* *}$ \\
\hline Destructive marital conflict & $\rightarrow$ & T2 externalizing problems & .05 & .02 & $2.25^{*}$ \\
\hline Constructive marital conflict & $\rightarrow$ & Negative parenting practices & -.01 & .03 & -.19 \\
\hline Constructive marital conflict & $\rightarrow$ & Positive parenting practices & .26 & .03 & $8.16^{* * *}$ \\
\hline Constructive marital conflict & $\rightarrow$ & Social skills & .09 & .03 & $2.68^{* *}$ \\
\hline Constructive marital conflict & $\rightarrow$ & T2 internalizing problems & -.03 & .03 & -1.09 \\
\hline Constructive marital conflict & $\rightarrow$ & T2 externalizing problems & -.01 & .02 & -.54 \\
\hline \multicolumn{6}{|l|}{ Parenting practice } \\
\hline Negative parenting practices & $\rightarrow$ & Social skills & -.10 & .03 & $-3.90^{* * *}$ \\
\hline Negative parenting practices & $\rightarrow$ & T2 internalizing problems & .07 & .02 & $3.30^{* * *}$ \\
\hline Negative parenting practices & $\rightarrow$ & T2 externalizing problems & .20 & .02 & $10.08^{* * *}$ \\
\hline Positive parenting practices & $\rightarrow$ & Social skills & .08 & .03 & $3.10^{* *}$ \\
\hline Positive parenting practices & $\rightarrow$ & T2 internalizing problems & -.05 & .02 & $-2.56^{* *}$ \\
\hline Positive parenting practices & $\rightarrow$ & T2 externalizing problems & -.10 & .02 & $-4.90^{* * *}$ \\
\hline \multicolumn{6}{|l|}{ Child social competence } \\
\hline Social skills & $\rightarrow$ & T2 internalizing problems & -.38 & .02 & $-18.65^{* * *}$ \\
\hline Social skills & $\rightarrow$ & T2 externalizing problems & -.45 & .02 & $-22.75^{* * *}$ \\
\hline \multicolumn{6}{|l|}{ Child adjustment } \\
\hline T1 internalizing problems & $\rightarrow$ & T2 internalizing problems & .50 & .02 & $27.03^{* * *}$ \\
\hline $\mathrm{T} 1$ externalizing problems & $\rightarrow$ & T2 externalizing problems & .39 & .02 & $21.30^{* * *}$ \\
\hline
\end{tabular}

${ }^{*} p<.05 ;{ }^{* *} p<.01 ;{ }^{* * *} p<.001$ 
parenting practices. This result suggests that destructive marital conflict is indirectly and negatively related to child mental health functioning through negative parenting practices in the relationship between SES and child mental health functioning. Simultaneously, in that relationship, destructive marital conflict was directly and negatively related to child mental health functioning. By contrast, these results indicate that constructive marital conflict demonstrates an indirect and positive relationship to child mental health functioning through positive parenting practices, as well as a direct positive relationship to child mental health functioning. (3) Social skills, which were associated with different types of family factors (i.e., SES, including family income and parental education levels, and both negative and positive dimensions of family processes), adversely affected later internalizing and externalizing behaviors. This result suggests social skills were lowered by the negative aspects of family processes (i.e., destructive marital conflict and negative parenting practices) and raised by the positive aspects of family processes (constructive marital conflict and positive parenting practices) in preschool, which reduced later symptoms of internalizing and externalizing problem behaviors in the first grade. That is, social skills in preschool played a potentially protective role in preventing later behavioral problems. Therefore, our longitudinal analysis supported the initial hypotheses.

\section{Path of family economic situation, family processes, and child mental health functioning}

In this study, family income was directly linked to marital conflict, parenting practices, and in turn, child mental health functioning (i.e., social competence and behavioral problems). This result is consistent with previous research findings identifying a direct path of family income to destructive marital conflict and negative parenting practices, and in turn, child outcomes [7, 28-30, $35,36,63]$. Furthermore, this result supports the FSM's prediction that family income affects children's socioemotional development through its influence on parents' psychological well-being and, therefore, the inter-parental relationship and parent/child interactions [15]. The result also supports the notion of negative spillover effects and is consistent with family systems theory [17, 18].

Conversely, we found a positive pathway within which a higher family economic status was associated with more constructive marital conflict, and in turn, more use of positive parenting practices, resulting in higher mental health functioning. This result supports the notion of the positive spillover effect, with the positive inter-parental relationship spilling over into the parent/child relationship, resulting in more positive parenting practices.
Similar to negative spillover effects and consistent with family systems theory [18], positive emotions from interparental relationships may transfer to parent/child relationships $[82,83]$. This result, that there is a positive spillover effect in the family process model, is an extension of previous studies.

Additionally, we found that family income was directly related to child mental health functioning (i.e., social competence and behavioral problems), while controlling for other variables. There are likely to be other factors that were not accounted for in our model. For example, the Family Investment Model (FIM), which is concerned with the advantages reaped by the developing child because of family wealth $[28,172,173]$, may explain this association. The FIM proposes that families with more economic resources can make significant investments in the development of their children, whereas those with lower incomes must invest in more immediate family needs $[1,7,174]$. Income enables families to invest in building their children's human capital. These investments in children involve several dimensions of goods and services, including parents' direct and indirect stimulation of learning (e.g., providing learning materials and activities, and support through advanced training and schools), the family's standard of living (e.g., adequate food, housing, clothing, medical care), and living in a more advantaged neighborhood environment that fosters a child's development $[7,175,176]$. According to this perspective, children in disadvantaged families tend to fare worse because they have limited access to resources that help them develop. Mayer demonstrated that children in disadvantaged families lived under worse conditions, owned fewer stimulating materials, and were less likely to engage in stimulating activities [176]. After controlling for other family background characteristics, these resources were associated with children's developmental outcomes [176]. Therefore, the apparent direct effect of family economic status found in the current study could possibly be mediated by factors that were not accounted for in our model. Future studies should investigate this possibility by including more family factors related to child mental health functioning in their models.

\section{Path of parental educational level, family processes, and child mental health functioning}

As mentioned earlier, despite the many studies completed in this area, few studies have simultaneously investigated the influence of family income and maternal and paternal education levels as predictors in the relationships between SES, family processes, and child mental health functioning $[6,7,28]$. Although most of the previous FSM studies have focused primarily on economic conditions, we suspect that they tend to capture a limited 
scope of the influence of educational achievement. In this study, both maternal and paternal educational levels were independently linked with parental functioning and parent/child interactions, and in turn, with child mental health functioning in a unified model, while controlling for economic conditions. In addition, this result also supports the notion of both positive and negative spillover effects $[17,18]$, as educational levels were positively related to higher levels of constructive marital conflict, and in turn, higher levels of positive parenting, resulting in better developmental outcomes. Therefore, the results regarding the effects of multiple components of SES, including family income and maternal and paternal education levels on child mental health functioning through distinct pathways, are an extension of those found in previous studies.

In terms of the relationship between educational level and marital conflict, the results of the current study are consistent with those of previous research showing educational attainment to be inversely related to destructive marital conflict [62], and parental educational attainment to be positively related to greater marital satisfaction and marital stability [30, 63-65]. More precisely, paternal education was linked to both destructive and constructive conflict; however, maternal education was linked to only constructive conflict. This might be due to difference of effect of maternal and paternal education on decision-making in the home. As mentioned earlier, previous studies have suggested that higher education helps parents strengthen their communication and problem-solving skills, and promotes effective problem solving between parents $[50,58]$. In addition, higher education tends to make fathers positively participate in decision-making in the home, whereas, fathers with lower education negatively participate [177-179]. Therefore, in this study, paternal education might more strongly affect both destructive and constructive than maternal education.

Furthermore, in terms of the relationship between educational level and parental involvement, we found that maternal education was associated with positive parenting practices, but not paternal education; however, both maternal and paternal education were linked to negative parenting practices. This result might indicate that the effects of parental education on involvement is larger for maternal education than for paternal. This might be due to mothers tending to be the main provider of care within the households of Japan. Many studies suggest that mothers assume the primary parenting role, in that mothers were found to be more intrusive toward father/child interactions [180-182]. In addition, this result is consistent with previous research findings. A large number of studies suggest higher maternal educational attainment to be positively related to positive parenting attitudes, such as talking to children warmly or supportively [72, 73], whereas lower educational levels have been found to be predictors of negative parenting, such as harshness and physical disciplinary tactics [33, 34, 183-185]. However, although many studies suggest maternal educational attainment is related to parenting attitudes, few studies have comparatively investigated the influence of paternal education levels on parental involvement. These results imply the possibility that both maternal and paternal educational levels are independently related to parenting attitudes.

One of the important mechanisms in the effect of parental education levels on family processes and children's development is likely to be parental knowledge about childrearing and child development. Lower levels of parental education are associated with negative parenting attitudes, such as physical and authoritarian disciplinary tactics [33, 34, 183-185]. It has been suggested that this is due to a lack of knowledge concerning the counterproductive outcomes of severe disciplinary responses and appropriate alternatives to harsh discipline [33, 183]. Higher levels of parental education have also been positively associated with sensitivity, positive regard, and cognitive stimulation of children [186]. Further, it has been suggested that higher educational levels are associated with increased knowledge about childrearing and child development, and more supportive parenting [72, 73]. Therefore, both maternal and paternal education levels may influence parenting attitudes, even when controlling for family income, whereas educational attainment affects parenting attitudes through the adverse effects of poor family economic situations on parents' mental wellbeing. Therefore, we assume that findings related to economic predictions based on the FSM are likely to reflect educational differences in SES as well. Educational levels are likely to play an important role in the relationships among SES, family processes, and child mental health functioning.

In addition, we found a direct association between parental education levels and child mental health functioning (i.e., social competence and behavioral problems), while controlling for other variables. There are likely to be other factors that were unaccounted for in our model. The FIM may also explain this mediating pathway to provide evidence for the plausibility of parental education level as an important aspect of the investment process $[1$, 7].

The model proposes that, similar to family income, parental education level has an influence on parental investments, and that these investments, in turn, will have a positive relationship with child development. Parents with higher education levels acquire more knowledge 
about child development, have a greater understanding of strategies to encourage social competence, and may be more effective in teaching children [72, 73, 187]. Families with higher educational levels and more knowledge about childrearing and child development may be more willing to make significant investments in their children's development. Despite the reasonableness of this hypothesized mediating process, there have been limited investigations into the impact of parental education level, in terms of the FIM.

However, some evidence is consistent with the aforementioned ideas. For example, a previous study found education level to be positively correlated with parental investments involving a more enriched and positive child-rearing environment, characterized by the availability of play and learning materials, and the organization and diversity of the physical environment [188].

Investment in this regard is not only material (e.g., reading materials, learning materials, neighborhood, health insurance, and quality of residence), but also emotional (e.g., parenting beliefs and behaviors) [189]. For example, more highly educated parents create a richer and more complex language environment for their children [190]. They also spend more time communicating with their children [173, 191]. A previous study found parental education to be positively related to children's language skills, including vocabulary and reading skills [192]. The richness of the language environment in inter-parental and parent/child interactions may mediate the association between parents' education levels and a child's productive vocabularies, and enhance the children's social competence. Therefore, there are likely to be other factors in family processes that were unaccounted for in our model. This result is likely to support the FIM, including its suggestion of parental educational attainment as an SES indicator.

More precisely, regarding the path between parental education and social competence, we found that paternal education was directly linked to social competence, but maternal education was not. There are likely to be other factors of paternal characteristic roles that were unaccounted for in our model, in addition to factors of the FIM. For instance, paternal involvement tends to be more physical and challenging than maternal [193, 194]. Physical and challenging play is an important component of human socialization [195, 196]. Father/child physical play is likely to help children learn to regulate their own behavior, and practice coping with failure or frustration and interpreting others' emotions. This is because father/ child physical play has been linked to children's emotionregulation and peer competence [196-199]. The positive association between father/child physical play and child social competence is a common empirical finding [195,
200-203]. In addition, several studies have suggested that fathers with higher educational levels tend to be more involved, have more positive engagement, and are more accessible to their children [78-80]. Therefore, fathers with higher educational levels might promote child social competence through not only factors of FIM, but also characteristic parental involvement, such as physical and challenging play.

Moreover, regarding the path between parental education and behavioral problems, we found that maternal education was both directly and indirectly linked to T2 internalizing behavior and externalizing behavior; however, the link for paternal education was only indirect. There are also likely to be other factors of maternal characteristic roles that were unaccounted for in our model. For instance, mothers with higher education tend to have higher quality of mother/child interactions, such as sensitivity and responsiveness [188, 204]. Past researchers have found that maternal sensitivity and responsiveness significantly shape children's cognitive development. Furthermore, cognitive competence deficits have also been reported as a vulnerability factor in causing behavioral problems [205-208]. Therefore, maternal educational achievement might affect behavioral problems through the effect of specific mother/child interactions.

Future studies should investigate the possibilities of the direct effect of parental education levels, as found in this study, being mediated by factors not accounted for in our model. This could be done by including more factors in future models.

\section{The role of social competence in the relationships among SES, family processes, and adjustment}

We focused on both negative child developmental outcomes (i.e., behavioral problems) and desirable child developmental outcomes (i.e., social competence) in the relationship between family factors (i.e., SES, marital conflict, and parenting practices) and child mental health functioning. We also highlighted the ways that family processes within the FSM promote positive developmental outcomes.

In the current study, social competence mediated the association between family factors and children's behavioral adjustment in a comprehensive model. SES was positively related to social competence and inversely related to internalizing and externalizing symptomatology, through positive and negative dimensions of parents' marital relationships and parenting styles. This result is an extension of those of previous studies, in which multidimensional family factors (i.e., SES, marital conflict, and parenting style) were related to both negative and positive outcomes in a comprehensive model. This result is consistent with several previous research findings 
identifying the direct individual path within which marital conflict and parenting practices are associated with child mental health functioning.

In terms of parenting practices and child mental health functioning, in this study, negative parenting practice was directly linked with poorer mental health functioning (i.e., poorer social skills, and more internalizing and externalizing problems). By contrast, positive parenting was directly linked to higher mental health functioning (i.e., better social skills and fewer internalizing and externalizing problems). Previous studies have suggested that negative parenting behaviors, such as harsh discipline, being emotionally neglectful, or demonstrating rejecting behaviors, are often associated with lower sociabilitycompetence and increased problem behaviors in children $[16,25,143]$, while positive parenting behaviors, such as emotional expressiveness, responsiveness, and support, have been shown to predict better empathy and social functioning in children [140-143].

Additionally, in terms of marital conflict and child mental health functioning, in this study, marital conflict was not only indirectly related to child outcomes through parenting practices, but also directly related to child outcomes. Parents' destructive marital conflict was directly linked with poorer mental health functioning (i.e., poorer social skills, and more symptoms of internalizing and externalizing problems). By contrast, parents' constructive conflict was directly linked to better mental health functioning (i.e., better social skills), and in turn, fewer symptoms of behavioral problems. These results are consistent with previous studies indicating that exposure to marital conflict is associated with different responses in children, depending on the type of inter-parental relationship [146, 209].

Many previous studies have shown that destructive marital conflict negatively affects social competence [144]. In addition, the relationships between inter-parental destructive conflict and negative psychological adjustment among children (e.g., internalizing symptoms and externalizing problems) are well established [146, 149, 209-211]. That is, destructive marital conflict has been shown to adversely influence children's social competence [212-215], internalizing symptoms [211, 216], and externalizing problems $[210,211]$. However, limited research has investigated the impact of constructive marital conflict on child mental health functioning. Therefore, the current result is an extension of those in previous studies, which demonstrated constructive marital conflict's direct association with child social development.

One of the important direct mechanisms of the effect of inter-parental relationship on children's development is likely to be modeling. According to social learning theory, children's social development can be influenced by modeling the behaviors and attitudes of significant persons in their lives, such as parents [217]. Child social development may be both positively and negatively related to parents' social development, due to the effects of modeling [218-220]. Consistent with the modeling mechanism proposed by the spillover hypothesis, children may directly model conflict behavior exhibited by their parents. In the case of destructive marital conflict, children whose parents resolve their problems through aggressive behavior are more likely to learn that aggression is an acceptable way of dealing with disagreements, and thus, may act aggressively when interacting with their peers [149, 221, 222]. Therefore, destructive marital conflict is likely to directly limit children's social development. By contrast, in the case of constructive marital conflict, children whose parents resolve problems through supportive cooperation are more likely to learn from the negotiations between their mothers and fathers during the decision-making process, allowing them a blueprint to communicate more effectively and efficiently when interacting with their peers [150]. Therefore, constructive marital conflict is likely to directly enhance social development.

In addition, in this study, social skills in preschool, which were affected by family factors, inversely predicted later internalizing and externalizing symptomatology in the first grade, after controlling for preschool behavioral symptomatology. This result is consistent with previous research. A number of studies have shown negative correlations between social competence and behavioral problems. Early social competence among children is an important predictor of later social adjustment and psychopathology [223-226]. For example, social competence promotes child development in a number of domains, including social adjustment and interpersonal relationships [223, 227, 228]. Conversely, social competence deficits have been linked to social maladjustment and several problem behaviors, including aggression and delinquency [105, 223, 229-234].

Previous studies have primarily examined individual relationships between different types of SES, marital conflict, parenting practices, social competence, and child outcomes, without considering these associations in a comprehensive model. However, when considering the complex relationships between these variables, social competence was adversely related to later behavioral problems, as a mediating mechanism in the link between SES and child adjustment. Preschool social competence played a potential protective role in preventing later behavioral problems in the first grade. This result is an extension of previous studies, in which social competence was found to influence later adjustment, as shown in the complex relationships among these variables. 
The prevailing model of prevention holds that reducing risk factors associated with adverse outcomes, and increasing protective factors that moderate the effects of exposure to risk, will reduce the possibility of later maladjustment [235]. The effectiveness of this approach towards prevention rests on the extent to which identified risk and protective factors are actually causal. Therefore, the current study findings, which focus on multidimensional family factors' simultaneous promotion of social competence among preschoolers, may provide an effective strategy for promoting later social adjustment among children.

\section{Limitations and future directions}

Our findings should be interpreted in light of several limitations. First, although this study's design was longitudinal, the design was partially cross-sectional, identifying the relationship between family factors and social competence at $\mathrm{T} 1$. The cross-sectional design poses several restrictions that make it difficult to assume causality among the factors. Statistical evidence from studies using a cross-sectional design may not be as informative as longitudinal data [236, 237]. Prior studies have found that children's mental health functioning influences interparental relationship and parenting styles, as well as the influence of inter-parental relationship and parenting styles on children's mental health functioning [238-241]. Children's mental health functioning and family factors are likely to influence each other. Furthermore, followup period of the current study was only 1 year. Although the transition period from early childhood to elementary school is an important period of mental development for children, 1 year may not be enough follow-up time to estimate the effects that have taken place, leading to the possibility of underestimating the impact of SES. Future studies should primarily focus on longitudinal research to examine the effects of family factors on later social competence. Specifically, it is necessary to have longitudinal research with surveys distributed at least three different time points and more long term to clarify the extent to which family factors flow through social competence to affect later behavioral problems.

Second, the majority of the data in this study (i.e., marital conflict, parenting practices, and child behavioral adjustment) was obtained from only mothers; therefore, there is a risk of reporting bias. This vulnerability to reporting bias can pose a serious potential problem to interpretation of the findings [242-245]. Single respondents views' toward family factors and child mental health functioning may be skewed either more positively or negatively, thus resulting in misleading findings. The arguments for the examination of the complex relationships between components of SES, family processes, and child mental functioning would seem to be not fully realized with data provided only from mothers. Paternal and maternal education levels or other background information may also influence their views of family factors and children's adaptive functioning; several studies have showed there are discrepancies between the views of fathers and mothers [246, 247]. Therefore, this study's data may obscure the extent to which paternal education is associated with the inter-parental relationship, parenting styles, and children's adaptive functioning, since information from the point of view of fathers was absent.

Furthermore, other factors may also influence the views of the informants. For example, regarding the interparental relationship, prior studies have shown that views of conflict vary across men and women; women tend to report more conflict episodes than men do, whether for the better or worse [248]. In addition, regarding parenting styles, the data provided by only maternal reports did not reveal information concerning fathers' involvement. Generally, fathers and mothers each have their own parenting styles. Many studies have shown that fathers and mothers play similar or complementary roles in terms of parenting behavior, simultaneously suggesting that their qualities of parenting behavior differ, in particular concerning the amount of physical play; fathering may prove to be more challenging [249-251].

Views of children's adaptive functioning behavior may vary across fathers, mothers, and children's teachers. Many study findings indicate that there are several discrepancies among informants, including fathers, mothers, and children's teachers. These discrepancies are particularly prevalent between children's parents and teachers, in terms of their assessment of the children's psychological well-being [242-245, 252]. The discrepancies may reflect children's symptoms, or the opportunities to observe them. Generally, it is not easy for parents to assess early maladaptive behaviors. In particular, parents have difficulty identifying behavior that is indicative of internalizing problems in young children. For instance, it is difficult for parents to distinguish behavior that is reflective of underlying psychopathology from behavior that is reflective of immaturity in self-regulatory competence. Conversely, teachers have the advantage of having the opportunity to observe the behavior of many other children simultaneously. Furthermore, behavioral problems are likely to be more apparent at school than at home. Therefore, obtaining teacher reports may be particularly important for young children to aid in the assessment and forecasting of their school maladjustment and mental health problems [253]. Furthermore, several studies have suggested that the combination of teacher and parent reports with independent assessments is more sensitive than either assessment alone 
[254]. Therefore, in future studies, reports from several dissimilar informants, including those from fathers and teachers, in addition to mothers, will be needed to more precisely evaluate how family factors affect child mental health functioning.

Third, in the current study, we did not consider the interplay between maternal and paternal education, or the interplay between positive and negative aspects of inter-parental functioning. We studied the independent contributions of both maternal and paternal education, and those of the positive and negative aspects of interparental functioning; the framework used in this study does not lead to an examination of the actual interplay among any of these factors.

Regarding parental education, we included the independent contributions of both maternal and paternal education level, as we expected each SES indicator, as a predictor, to be differentially associated with family processes and child mental functioning through distinct pathways. However, the argument is incomplete and not generally consistent with theoretical perspectives, including family systems and developmental systems theories [1-5]. Theoretical perspectives suggest there is a more dynamic interplay than the simple additive contribution of maternal and paternal education. Not modeling the interaction between maternal and paternal education achievement may mislead the influence of each maternal and paternal education achievement.

Regarding inter-parental functioning, we also included the independent contributions of both positive and negative aspects of inter-parental functioning, as there are reasons we expected each positive and negative aspect of inter-parental functioning to be differentially associated with other variables through distinct pathways. Most studies empirically investigating the FSM have focused exclusively on the negative aspect of inter-parental functioning $[15,37]$. Previous research suggests the interplay between the positive and negative aspects of inter-parental functioning is more complex than simply looking at the independent contributions of each [15, 37]. Previous research also suggests that it is not easy to distinguish the positive and negative aspects of inter-parental functioning, and that children respond to the whole instead of just the parts [29, 37-39]. The model including the independent contributions of both the positive and negative aspects of inter-parental functioning may not precisely assess the influences of each. Therefore, the inclusion of maternal and paternal education, and the positive and negative aspects of inter-parental functioning are both strengths and weaknesses of this study.

Fourth, we could not exactly assess the positive aspects of inter-parental functioning as a constructive marital conflict. As mentioned earlier, we used the Quality of
Co-parental Communication (QCCS) measure to assess the positive and negative aspects of inter-parental functioning. The QCCS captures two aspects of the interparental relationship: Co-parental Conflict (only the negative side); and Co-parental Support (general helpfulness, resourcefulness, and cooperation) [152]. The Support subscales of this scale measured only "general support"; it has not precisely measured the constructive aspects of conflict. However, in the current study, we treated Co-parental Support, as measured by the Support subscales, as constructive conflict. Thus, the "constructive conflict" we used may not precisely assess the influence of the positive aspects of inter-parental functioning on the other variables. Future studies should investigate this possibility further by using other scales to more precisely assess the constructive aspects of conflict.

Fifth, there are likely to be other factors that were not accounted for in our model. As mentioned earlier, we found a direct association between SES and child mental health functioning, while controlling for other variables. There are likely to be other family environmental factors (e.g., child-rearing environment and more factors of the inter-parental relationship and child/parent interaction). Furthermore, although we found the effects of certain hypothesized family environmental factors on child mental health functioning, we did not consider genetic factors in our model; it is important to realize children's behavioral problems may be influenced by genetic risks, as well as their family's environmental factors. A large body of evidence supports the conclusion that children's behavioral problems are moderately heritable [255-258].

Several studies have suggested the extent to which children's mental health functioning is affected by family environmental factors depends on genetic and early temperamental characteristics; environments help determine how genes express themselves [259-261]. Children with different genetic attributes will respond differentially to the same environmental circumstances. Therefore, it is difficult to distinguish genetic effects from the effects of family environmental factors on child mental health functioning because genetic factors were not examined in this model. Consequently, there are likely to be other family environmental and genetic factors that need to be included in this model. Future studies should investigate this possibility further by including more family environmental factors related to child mental health functioning. Specifically, these studies could include a genetically informative design (e.g., a twin or adoption study design), as these types of studies would be useful in accounting for the interplay between individuals and environmental circumstances.

Furthermore, although we described earlier that the FIM contends that family SES is associated with 
neighborhood conditions as one aspect of parental investment, our studies did not assess areal characteristics (i.e., neighborhood conditions). Family's socioeconomic resources are likely to largely determine the kind of neighborhood in which they reside [262]. Wealthier parents are expected to reside in areas that have a positive community environment, which provides resources for the developing child, such as parks, good schools, community involvement among residents, and access to conventional friends. Conversely, poor parents are constrained in their choice of neighborhoods. Children reared in neighborhoods without these resources experience a number of negative consequences. Lower income may lead to residing in extremely poor neighborhoods, which are characterized by few resources for child development, such as playgrounds, childcare, health care facilities, and after-school programs. Children who live in areas of disadvantaged neighborhoods tend to have poor physical and mental health [263, 264]. Furthermore, several studies suggest that the affluence of neighborhoods is associated with child outcomes over and above family poverty [265]. Thus, future studies will need to include an assessment of neighborhood quality.

Finally, these findings may not be generalizable to all families, because there is a risk of attrition bias, and the sample was drawn from a limited geographical area in an urban metropolis of Japan. As mentioned earlier, the retention rate from $\mathrm{T} 1$ to $\mathrm{T} 2$ was $51.6 \%$, and the $\mathrm{T} 2$ returning participants tended to be relatively higher in SES than the non-returning participants. This indicates there is a risk of attrition bias. Therefore, there is the possibility that our analyses could not exactly evaluate the mechanism of children with lower SES, and our analyses may underestimate the influence of SES. Furthermore, some characteristics of Japanese society, such as low levels of economic disparity and high education levels among the general population, may have contributed towards the current results. The reproducibility of the current results should be confirmed using data from other regions in a variety of settings. In summary, future research on these topics would benefit from longitudinal designs and samples with higher retention rates (in particular, lower SES participants), and greater demographic and clinical diversity.

\section{Conclusions}

Despite the above-mentioned limitations, our findings help advance our understanding of the relationships between different types of SES, marital relationships, parenting styles, and child social competence and behavioral problems. This study highlights the need to simultaneously explore the interrelations between multiple family factors to further our understanding of child mental health functioning.

Emphasis is placed on the importance of examining both family income and educational levels of parents as SES indicators, to elucidate the relationships between family factors and child adjustment. Additionally, consistent with a developmental psychopathology perspective, this study emphasizes the need to explore both positive and negative aspects of family processes (i.e., marital relationships and parenting styles), with a particular focus on the positive dimensions of family functioning. This study also emphasizes social competence as a potential protective factor that prevents later behavioral problems.

The current study advances the understanding of SES, marital conflict, and parenting, utilizing a family systems explanation for child development. (1) This study adds to previous literature concerning the relationship between SES and child mental health outcomes by demonstrating that both family income and parental education levels simultaneously and independently influence child mental health outcomes through marital conflict and parenting practices. In addition, (2) the current study adds to previous literature concerning the relationship between SES and child mental health functioning, by demonstrating the positive pathway where constructive marital conflict was shown to be related to higher levels of affirmative parenting and, in turn, more positive outcomes. The current study supports not only the notion of negative spillover effects, but also of positive spillover effects. In addition, (3) social skills, which were affected by multidimensional family factors (i.e., SES, including family income and parental education levels, and both positive and negative dimensions of family processes), adversely influenced later internalizing and externalizing behaviors. Therefore, our study suggests the possibility that theoretical models, including the FSM, should be included with parental educational levels and positive aspects of family functioning and child outcomes when examining the effects of SES.

These findings offer preliminary evidence for the need to explore SES by including family income and parental educational levels, and both negative and positive aspects of family functioning. They advance our understanding of SES, marital conflict, and parenting practices, using a family systems explanation for child development. Therefore, our results suggest that we should be sensitive to social inequalities in children's mental health problems and developmental outcomes, and strive to reduce social inequalities. In the long-term, it may be necessary to focus not only on economic support, but also on education, as providing equal access to suitable educational 
opportunities can positively affect the next generation, and is likely to have a more permanent impact on the child-rearing environment than a temporary increase in income. If more parents can become better educated through an improved social system, it might lead to better developmental outcomes for children. In addition, simultaneously focusing on the marital relationship and parenting style in negative and positive domains may be an effective strategy for developing social adjustment among children. The current study suggests that marital relationships and parenting skills in negative and positive domains may be appropriate for interventions promoting social competence among children to prevent later social maladjustment among parents and children who are socioeconomically disadvantaged. Our findings have important clinical and policy implications.

\section{Abbreviations}

QCCS: The Quality of Co-parental Communication Scale; APQ: The Alabama Parenting Questionnaire; SSQ: The Social Skills Questionnaire; SDQ: The Strengths and Difficulties Questionnaire.

\section{Authors' contributions}

$\mathrm{RH}$ designed and managed the study, performed the statistical analyses, and drafted the manuscript. TK administered and supervised the overall conduct of the study. Both authors read and approved the final manuscript.

\section{Author details}

${ }^{1}$ School of Nursing, Nagoya City University, Mizuho-cho, Mizuho-ku, Nagoya 467-8601, Japan. ${ }^{2}$ Graduate School of Medicine, Kyoto University, Kyoto, Japan.

\section{Acknowledgements}

We gratefully acknowledge all the children, parents, and preschool teachers who participated in this study. In addition, we are grateful to the reviewers for their helpful and constructive comments concerning this manuscript.

\section{Competing interests}

The authors declare that they have no competing interests.

\section{Availability of data and materials}

The datasets supporting the conclusions of this article are included within the manuscript.

\section{Consent for publication \\ Not applicable.}

\section{Ethics approval and consent to participate}

The children's parents and teachers were informed of the study's purpose and procedures, and they were made aware that they were not obligated to participate. The teachers provided their written informed consent, and the parents submitted the same on behalf of their children prior to participating in this research. Ethical approval for this study was obtained from Kyoto University's Ethics Committee in Kyoto, Japan (E2322).

\section{Funding}

This work was supported by JSPS KAKENHI Grant Number 26893224.

\section{Publisher's Note}

Springer Nature remains neutral with regard to jurisdictional claims in published maps and institutional affiliations.

Received: 7 February 2017 Accepted: 7 December 2017

Published online: 19 December 2017
References

1. Bradley RH, Corwyn RF. Socioeconomic status and child development Annu Rev Psychol. 2002;53:371-99. https://doi.org/10.1146/annurev. psych.53.100901.135233.

2. Letourneau NL, Duffett-Leger L, Levac L, Watson B, YoungMorris $C$. Socioeconomic status and child development: a meta-analysis. J Emot Behav Disord. 2011;21:211-24. https://doi. org/10.1177/1063426611421007.

3. Poulton R, Caspi A, Milne BJ, Thomson WM, Taylor A, Sears MR, et al. Association between children's experience of socioeconomic disadvantage and adult health: a life-course study. Lancet. 2002;360:1640-5. https://doi.org/10.1016/S0140-6736(02)11602-3.

4. Oakes JM, Rossi PH. The measurement of SES in health research: current practice and steps toward a new approach. Soc Sci Med. 2003;56:76984. https://doi.org/10.1016/S0277-9536(02)00073-4.

5. Haas SA. Health selection and the process of social stratification: the effect of childhood health on socioeconomic attainment. J Health Soc Behav. 2006;47:339-54. https://doi.org/10.1177/002214650604700403.

6. Bøe T, Sivertsen B, Heiervang E, Goodman R, Lundervold AJ, Hysing M. Socioeconomic status and child mental health: the role of parental emotional well-being and parenting practices. J Abnorm Child Psychol. 2014;42:705-15. https://doi.org/10.1007/s10802-013-9818-9.

7. Conger RD, Conger KJ, Martin MJ. Socioeconomic status, family processes, and individual development. J Marriage Fam. 2010;72:685-704. https://doi.org/10.1111/j.1741-3737.2010.00725.x.

8. Castillo J, Welch G, Sarver C. Fathering: the relationship between fathers' residence, fathers' sociodemographic characteristics, and father involvement. Matern Child Health J. 2011;15:1342-9. https://doi.org/10.1007/ s10995-010-0684-6.

9. Volling BL, Belsky J. Multiple determinants of father involvement during infancy in dual-earner and single-earner families. J Marriage Fam. 1991;53:461-74. https://doi.org/10.2307/352912.

10. Dearing E, McCartney K, Taylor BA. Change in family income-to-needs matters more for children with less. Child Dev. 2001;72:1779-93. https:// doi.org/10.1111/1467-8624.00378.

11. Han W. Maternal nonstandard work schedules and child cognitive outcomes. Child Dev. 2005;76:137-54. https://doi. org/10.1111/j.1467-8624.2005.00835.x.

12. Kohen DE, Brooks-Gunn J, Leventhal T, Hertzman C. Neighborhood income and physical and social disorder in Canada: associations with young children's competencies. Child Dev. 2002;73:1844-60. https:// doi.org/10.1111/1467-8624.t01-1-00510.

13. Mills-Koonce WR, Willoughby MT, Garrett-Peters P, Wagner N, VernonFeagans L, Family Life Project Key Investigators, The Family Life Project Key Investigators. The interplay among socioeconomic status, household chaos, and parenting in the prediction of child conduct problems and callous-unemotional behaviors. Dev Psychopathol. 2016;28:757-71. https://doi.org/10.1017/S0954579416000298.

14. Schoppe-Sullivan SJ, Schermerhorn AC, Cummings EM. Marital conflict and children's adjustment: evaluation of the parenting process model. J Marriage Fam. 2007;69:1118-34. https://doi. org/10.1111/j.1741-3737.2007.00436.x.

15. Parke RD, Coltrane S, Duffy S, Buriel R, Dennis J, Powers J, et al. Economic stress, parenting, and child adjustment in Mexican American and European American families. Child Dev. 2004;75:1632-56. https://doi. org/10.1111/j.1467-8624.2004.00807.x.

16. Repetti RL, Taylor SE, Seeman TE. Risky families: family social environments and the mental and physical health of offspring. Psychol Bull. 2002;128:330-66. https://doi.org/10.1037/0033-2909.128.2.330.

17. Krishnakumar A, Buehler C. Interparental conflict and parenting behaviors: a meta-analytic review. Fam Relat. 2000;49:25-44. https://doi. org/10.1111/j.1741-3729.2000.00025.x

18. Sturge-Apple ML, Davies PT, Cummings EM. Impact of hostility and withdrawal in interparental conflict on parental emotional unavailability and children's adjustment difficulties. Child Dev. 2006;77:1623-41. https://doi.org/10.1111/j.1467-8624.2006.00963.x.

19. Gresham FM. Conceptual issues in the assessment of social competence in children. In: Strain P, Guralnick M, Walker H, editors. Children's social behavior: development, assessment, and modification. New York: Academic Press; 1986. p. 143-80. 
20. Rubin $\mathrm{KH}$, Rose-Krasnor L. Interpersonal problem solving and social competence in children. In: Van Hasselt VB, Hersen M, editors. Handbook of social development: a lifespan perspective. New York: Plenum; 1992. p. 283-323.

21. Bolger KE, Patterson CJ, Thompson WW, Kupersmidt JB. Psychosocia adjustment among children experiencing persistent and intermittent family economic hardship. Child Dev. 1995;66:1107-29. https://doi. org/10.2307/1131802.

22. Reiss F. Socioeconomic inequalities and mental health problems in children and adolescents: a systematic review. Soc Sci Med. 2013;90:24-31. https://doi.org/10.1016/j.socscimed.2013.04.026.

23. McLoyd VC. Socioeconomic disadvantage and child development. Am Psychol. 1998;53:185-204. https://doi. org/10.1037/0003-066X.53.2.185.

24. Starfield B, Robertson J, Riley AW. Social class gradients and health in childhood. Ambul Pediatr. 2002;2:238-46. https://doi. org/10.1367/1539-4409(2002)002<0238:SCGAHI>2.0.CO;2.

25. Dodge K, Pettit G, Bates J. Socialization mediators of the relation between socioeconomic status and child conduct problems. Child Dev. 1994;65:649-65. https://doi.org/10.2307/1131407.

26. Duncan GJ, Brooks-Gunn J, Klebanov PK. Economic deprivation and early childhood development. Child Dev. 1994;65:296-318. https://doi. org/10.2307/1131385

27. Raviv T, Kessenich M, Morrison FJ. A mediational model of the association between socioeconomic status and three-year-old language abilities: the role of parenting factors. Early Child Res Q. 2004;19:528-47. https://doi.org/10.1016/j.ecresq.2004.10.007

28. Conger RD, Donnellan MB. An interactionist perspective on the socioeconomic context of human development. Annu Rev Psychol. 2007:58:175-99. https://doi.org/10.1146/annurev. psych.58.110405.085551.

29. Cutrona CE, Russell DW, Abraham WT, Gardner KA, Melby JN, Bryant $C$, et al. Neighborhood context and financial strain as predictors of marital interaction and marital quality in African American couples. Pers Relatsh. 2003;10:389-409. https://doi.org/10.1111/1475-6811.00056.

30. Rauer AJ, Karney BR, Garvan CW, Hou W. Relationship risks in context: a cumulative risk approach to understanding relationship satisfaction. J Marriage Fam. 2008;70:1122-35. https://doi. org/10.1111/j.1741-3737.2008.00554.x.

31. Choi H, Marks NF. Marital quality, socioeconomic status, and physical health. J Marriage Fam. 2013;75:903-19. https://doi.org/10.1111/ jomf.12044.

32. Gomel JN, Tinsley BJ, Parke RD, Clark KM. The effects of economic hardship on family relationships among African American, Latino, and Euro-American families. J Fam Issues. 1998;19:436-67. https://doi. org/10.1177/019251398019004004.

33. Dietz TL. Disciplining children: characteristics associated with the use of corporal punishment. Child Abuse Negl. 2000;24:1529-42. https://doi. org/10.1016/S0145-2134(00)00213-1.

34. Jansen PW, Raat H, Mackenbach JP, Hofman A, Jaddoe VWV, BakermansKranenburg MJ, et al. Early determinants of maternal and paternal harsh discipline: the generation R study. Fam Relat. 2012;61:253-70. https:// doi.org/10.1111/j.1741-3729.2011.00691.x.

35. Hashima PY, Amato PR. Poverty, social support, and parental behavior. Child Dev. 1994;65:394-403. https://doi.org/10.1111/j.1467-8624.1994. tb00758.x.

36. Hart B, Risley TR. American parenting of language-learning children: persisting differences in family-child interactions observed in natural home environments. Dev Psychol. 1992;28:1096-105. https://doi. org/10.1037/0012-1649.28.6.1096.

37. Conger R, Wallace L, Sun Y, Simons R, McLoyd V, Brody G. Economic pressure in African American families: a replication and extension of the family stress model. Dev Psychol. 2002;38:179-93. https://doi. org/10.1037/0012-1649.38.2.179.

38. Conger RD, Conger KJ. Resilience in midwestern families: selected findings from the first decade of a prospective, longitudinal study. J Marriage Fam. 2002;64:361-73. https://doi. org/10.1111/j.1741-3737.2002.00361.x.

39. Cutrona CE, Russell DW, Burzette R, Wesner K, Bryant C. Predicting relationship stability among midlife African American couples. J Consult Clin Psychol. 2011;79:814-25. https://doi.org/10.1037/a0025874.
40. Krieger N, Williams DR, Moss NE. Measuring social class in US public health research: concepts, methodologies, and guidelines. Annu Rev Public Health. 1997;18:341-78. https://doi.org/10.1146/annurev. publhealth.18.1.341.

41. Jefferson AL, Gibbons LE, Rentz DM, Carvalho JO, Manly J, Bennett DA Jones RN. A life course model of cognitive activities, socioeconomic status, education, reading ability, and cognition. J Am Geriatr Soc. 2011;59:1403-11. https://doi.org/10.1111/j.1532-5415.2011.03499.x.

42. Moretti E. Estimating the social return to higher education: evidence from longitudinal and repeated cross-sectional data. J Econ. 2004;121:175-212. https://doi.org/10.1016/j.jeconom.2003.10.015.

43. Sacerdote B. Peer effects with random assignment: results for Dartmouth roommates. Q J Econ. 2001;116:681-704. https://doi. org/10.1162/00335530151144131.

44. Lewis SK, Ross CE, Mirowsky J. Establishing a sense of personal control in the transition to adulthood. Soc Forces. 1999;77:1573-99. https://doi. org/10.2307/3005887

45. Gjonça E, Tabassum F, Breeze E. Socioeconomic differences in physical disability at older age. J Epidemiol Commun Health. 2009;63:928-35. https://doi.org/10.1136/jech.2008.082776.

46. Chuang NK, Walker K, Caine-Bish N. Student perceptions of caree choices: the impact of academic major. J Fam Consum Sci Educ. 2009;27:18-29.

47. Fujishiro K, Xu J, Gong F. What does "occupation" represent as an indicator of socioeconomic status? Exploring occupational prestige and health. Soc Sci Med. 2010;71:2100-7. https://doi.org/10.1016/j. socscimed.2010.09.026.

48. Becker GS. Human capital: a theoretical and empirical analysis. New York: National Bureau of Economic Research; 1964.

49. Becker GS. A theory of marriage: part II. J Polit Econ. 1974;82:S11-26. https://doi.org/10.1086/260287.

50. Lundberg S, Pollak RA. Efficiency in marriage. Rev Econ Househ. 2003:1:153-67. https://doi.org/10.1023/A:1025041316091.

51. Rossetti S, Tanda P. Human capital, wages and family interactions. Labour. 2000;14:5-34. https://doi.org/10.1111/1467-9914.00122.

52. Huang C, Li H, Liu P, Zhang J. Why does spousal education matter for earnings? Assortative mating and cross-productivity. J Labor Econ. 2009;27:633-52. https://doi.org/10.1086/644746.

53. Tiefenthaler J. The productivity gains of marriage: effects of spousal education on own productivity across market sectors in brazil. Econ Dev Cult Change. 1997;45:633-50. https://doi.org/10.1086/452294.

54. Jepsen LK. The relationship between wife's education and husband's earnings: evidence from 1960-2000. Rev Econ Househ. 2005;3:197-214. https://doi.org/10.1007/s11150-005-0710-4.

55. Lefgren L, Mclntyre F. The relationship between women's education and marriage outcomes. J Labor Econ. 2006:24:787-830. https://doi. org/10.1086/506486.

56. Mano Y, Yamamura E. Effects of husband's education and family structure on labor force participation and married Japanese women's earnings. Jpn Econ. 2011;38:71-91. https://doi.org/10.2753/ JES1097-203X380303.

57. Benham L. Benefits of women's education within marriage. J Polit Econ. 1974:82:57-71. https://doi.org/10.1086/260291.

58. Mirowsky J, Ross CE. Social causes of psychological distress. 2nd ed. New York: Aldine de Gruyter; 2003.

59. Schudlich T, Norman J, Du Nann B, Wharton A, Block M, Nicol H, Dachenhausen M, Gleason A, Pendergast K. Interparental conflicts in dyadic and triadic contexts: parental depression symptoms and conflict history predict differences. J Child Fam Stud. 2015;2014(24):1047-59. https://doi.org/10.1007/s10826-014-9914-7.

60. Simon RW. Revisiting the relationships among gender, marital status, and mental health. Am J Sociol. 2002;107:1065-96. https://doi. org/10.1086/339225.

61. Dush CMK, Taylor MG, Kroeger RA. Marital happiness and psychological well-being across the life course. Fam Relat. 2008;57:211-26. https://doi. org/10.1111/j.1741-3729.2008.00495.x

62. Schoen R, Rogers SJ, Amato PR. Wives' employment and spouses' marital happiness: assessing the direction of influence using longitudinal couple data. J Fam Issues. 2006;27:506-28. https://doi.org/10.1177/019 $2513 \times 05283983$ 
63. Dakin J, Wampler R. Money doesn't buy happiness, but it helps: marital satisfaction, psychological distress, and demographic differences between low- and middle-income clinic couples. Am J Fam Ther. 2008;36:300-11. https://doi.org/10.1080/01926180701647512.

64. Heaton TB. Factors contributing to increasing marital stability in the United States. J Fam Issues. 2002;23:392-409. https://doi.org/10.1177/0 $192513 \times 02023003004$.

65. Orbuch TL, Veroff J, Hassan H, Horrocks J. Who will divorce: a 14-year longitudinal study of black couples and white couples. J Soc Pers Relatsh. 2002;19:179-202. https://doi.org/10.1177/0265407502192002.

66. Bornstein MH, Hahn C, Suwalsky J, Haynes OM. Socioeconomic status, parenting, and child development: the Hollingshead four-factor index of social status and the socioeconomic index of occupations. In: Bornstein MH, Bradley RH, editors. Socioeconomic status, parenting, and child development. Mahwah: Erlbaum; 2003. p. 29-82.

67. Dix T. The affective organization of parenting: adaptive and maladaptive processes. Psychol Bull. 1991;110:3-25. https://doi. org/10.1037/0033-2909.110.1.3.

68. Cox MJ, Paley B. Families as systems. Annu Rev Psychol. 1997;48:243-67. https://doi.org/10.1146/annurev.psych.48.1.243.

69. Feldman MA, Varghese J, Ramsay J, Rajska D. Relationship between social support, stress and mother-child interactions in mothers with intellectual disabilities. J Appl Res Intellect Disabil. 2002;15:314-23. https://doi.org/10.1046/j.1468-3148.2002.00132.x.

70. Sobolewski JM, Amato PR. Economic hardship in the family of origin and children's psychological well-being in adulthood. J Marriage Fam. 2005;67:141-56. https://doi.org/10.1111/j.0022-2445.2005.00011.x.

71. Brassell AA, Rosenberg E, Parent J, Rough JN, Fondacaro K, Seehuus M. Parent's psychological flexibility: associations with parenting and child psychosocial well-being. J Contextual Behav Sci. 2016;5:111-20. https:// doi.org/10.1016/j.jcbs.2016.03.001

72. Morawska A, Winter L, Sanders MR. Parenting knowledge and its role in the prediction of dysfunctional parenting and disruptive child behaviour. Child Care Health Dev. 2009;35:217-26. https://doi. org/10.1111/j.1365-2214.2008.00929.x.

73. Waylen A, Stewart-Brown S. Factors influencing parenting in early childhood: a prospective longitudinal study focusing on change. Child Care Health Dev. 2010;36:198-207. https://doi. org/10.1111/j.1365-2214.2009.01037.x.

74. Bradley RH, Caldwell BM. Caregiving and the regulation of child growth and development: describing proximal aspects of caregiving systems. Dev Rev. 1995;15:38-85. https://doi.org/10.1006/drev.1995.1002.

75. Barber B, Stolz H, Olsen J, Collins A, Burchinal M. Parental support, psychological control, and behavioral control: assessing relevance across time, culture, and method: abstract. Monogr Soc Res Child Dev. 2005;70:135-7. https://doi.org/10.1111/j.1540-5834.2005.00365.x.

76. Dallaire $\mathrm{DH}$, Weinraub $\mathrm{M}$. The stability of parenting behaviors over the first 6 years of life. Early Child Res Q. 2005;20:201-19. https://doi. org/10.1016/j.ecresq.2005.04.008.

77. Waylen A, Stallard N, Stewart-Brown S. Parenting and health in midchildhood: a longitudinal study. Eur J Public Health. 2008;18:300-5. https://doi.org/10.1093/eurpub/ckm131.

78. Blair SL, Wenk D, Hardesty C. Marital quality and paternal involvement: interconnections of men's spousal and parental roles. J Mens Stud. 1994;2:221-37. https://doi.org/10.3149/jms.0203.221.

79. King V, Harris KM, Heard HE. Racial and ethnic diversity in nonresident father involvement. J Marriage Fam. 2004;66:1-21. https://doi. org/10.1111/j.1741-3737.2004.00001.x.

80. Lerman $\mathrm{R}$, Sorensen E. Father involvement with their nonmarital children: patterns, determinants, and effects on their earnings. Marriage Fam Rev. 2000;29:137-58. https://doi.org/10.1300/J002v29n02_09.

81. Engfer A. The interrelatedness of marriage and the mother-child relationship. In: Hinde RA, Stevenson-Hinde J, editors. Relationships within families: mutual influences. Oxford: Clarendon Press; 1988. p. 104-18.

82. Cox MJ, Paley B. Understanding families as systems. Curr Dir Psychol Sci. 2003:12:193-6. https://doi.org/10.1111/1467-8721.01259.

83. Rinaldi CM, Howe N. Perceptions of constructive and destructive conflict within and across family subsystems. Infant Child Dev. 2003;12:441-59. https://doi.org/10.1002/icd.324.
84. Cummings EM, Goeke-Morey M, Papp L. Children's responses to everyday marital conflict tactics in the home. Child Dev. 2003;74:1918-29. https://doi.org/10.1046/j.1467-8624.2003.00646.X.

85. Goeke-Morey MC, Cummings EM, Harold GT, Shelton KH. Categories and continua of destructive and constructive marital conflict tactics from the perspective of US and Welsh children. J Fam Psychol. 2003;17:327-38. https://doi.org/10.1037/0893-3200.17.3.327.

86. Coln KL, Jordan SS, Mercer SH. A unified model exploring parenting practices as mediators of marital conflict and children's adjustment Child Psychiatry Hum Dev. 2013;44:419-29. https://doi.org/10.1007/ s10578-012-0336-8.

87. McCoy KP, George MRW, Cummings EM, Davies PT. Constructive and destructive marital conflict, parenting, and children's school and social adjustment. Soc Dev. 2013;22:641-62. https://doi.org/10.1111/ sode. 12015.

88. Du Rocher schudlich TD, Cummings EM. Parental dysphoria and childrens internalizing symptoms: marital conflict styles as mediators of risk. Child Dev. 2003;74:1663-81. https://doi. org/10.1046/j.1467-8624.2003.00630.x.

89. Elliott SN, Busse RT. Social skills assessment and intervention with children and adolescents: guidelines for assessment and training procedures. Sch Psychol Int. 1991;12:63-83. https://doi. org/10.1177/0143034391121006.

90. Gresham FM, Elliott SN. Social skills rating system. Circle Pines: American Guidance Service; 1990.

91. Sheridan SM, Walker D. Social skills in context: considerations for assessment, intervention, and generalization. In: Reynolds CR, Gutkin TB, editors. The handbook of school psychology. 3rd ed. New York: Wiley; 1999. p. 686-708.

92. Birch SH, Ladd GW. The teacher-child relationship and children's early school adjustment. J Sch Psychol. 1997;35:61-79. https://doi. org/10.1016/S0022-4405(96)00029-5.

93. Birch SH, Ladd GW. Children's interpersonal behaviors and the teacher-child relationship. Dev Psychol. 1998;34:934-46. https://doi. org/10.1037/0012-1649.34.5.934.

94. Hamre BK, Pianta RC. Early teacher-child relationships and the trajectory of children's school outcomes through eighth grade. Child Dev. 2001;72:625-38. https://doi.org/10.1111/1467-8624.00301.

95. Ladd GW, Burgess KB. Do relational risks and protective factors moderate the linkages between childhood aggression and early psychological and school adjustment? Child Dev. 2001;72:1579-601. https://doi. org/10.1111/1467-8624.00366.

96. Mischel W, Shoda Y, Peake PK. The nature of adolescent competencies predicted by preschool delay of gratification. J Pers Soc Psychol. 1988;54:687-96. https://doi.org/10.1037/0022-3514.54.4.687.

97. Parker JG, Asher SR. Peer relations and later personal adjustment: are low-accepted children at risk? Psychol Bull. 1987;102:357-89. https:// doi.org/10.1037/0033-2909.102.3.357.

98. Coie JD, Dodge KA. Multiple sources of data on social behavior and social status in the school: a cross-age comparison. Child Dev. 1988;59:815-29. https://doi.org/10.1111/j.1467-8624.1988.tb03237.x.

99. Eisenberg N, Fabes R. Prosocial development. In: Damon W, Eisenberg $\mathrm{N}$, editors. Handbook of child psychology. Social, emotional, and personality development, vol. 3. 5th ed. New York: Wiley; 1998. p. 701-78.

100. McClelland MM, Morrison FJ. The emergence of learning-related social skills in preschool children. Early Child Res Q. 2003;18:206-24. https:// doi.org/10.1016/50885-2006(03)00026-7

101. Campbell S. Hard-to-manage preschool boys: externalizing behavior, social competence, and family context at 2-year follow-up. J Abnorm Child Psychol. 1994;22:147-66. https://doi.org/10.1007/BF02167897.

102. Olson S, Hoza B. Preschool development antecedents of conduct problems in children beginning school. J Clin Child Psychol. 1993;22:60-7. https://doi.org/10.1207/s15374424jccp2201_6.

103. Achenbach TM, Howell CT, Quay HC, Conners CK. National survey of problems and competencies among four- to sixteen-year-olds: parents' reports for normative and clinical samples. Monogr Soc Res Child Dev. 1991;56:1-131. https://doi.org/10.2307/1166156.

104. Allen K, Prior M. Assessment of the validity of easy and difficult temperament through observed mother-child behaviours. Int J Behav Dev. 1995;18:609-30. https://doi.org/10.1177/016502549501800403. 
105. Bates J. Conceptual and empirical linkages between temperament and behavior problems: a commentary on the Sanson, Prior, and Kyrios study. Merrill Palmer Q. 1990;36:193-9.

106. Campbell SB. Behavior problems in preschool children: a review of recent research. J Child Psychol Psychiatry. 1995;36:113-49. https://doi. org/10.1111/j.1469-7610.1995.tb01657.x.

107. Campbell SB, Pierce EW, March CL, Ewing LJ, Szumowski EK. Hard-to-manage preschool boys: symptomatic behavior across contexts and time. Child Dev. 1994;65:836-51. https://doi. org/10.1111/j.1467-8624.1994.tb00787.x.

108. Caspi A, Henry B, McGee RO, Moffitt TE, Silva PA. Temperamental origins of child and adolescent behavior problems: from age three to age fifteen. Child Dev. 1995;66:55-68. https://doi. org/10.1111/j.1467-8624.1995.tb00855.x

109. Caron C, Rutter M. Comorbidity in child psychopathology: concepts, issues and research strategies. J Child Psychol Psychiatry. 1991;32:106380. https://doi.org/10.1111/j.1469-7610.1991.tb00350.x

110. Mathiesen KS, Sanson A. Dimensions of early childhood behavior problems: stability and predictors of change from 18 to 30 months. J Abnorm Child Psychol. 2000;28:15-31. https://doi.org/10.102 3/A:1005165916906.

111. Kerr M, Tremblay RE, Pagani L, Vitaro F. Boys'behavioral inhibition and the risk of later delinquency. Arch Gen Psychiatry. 1997;54:809-16. https://doi.org/10.1001/archpsyc.1997.01830210049005.

112. PanakWF, Garber J. Role of aggression, rejection, and attributions in the prediction of depression in children. Dev Psychopathol. 1992;4:145-65. https://doi.org/10.1017/S0954579400005617.

113. Lahey BB, Loeber R, Burke J, Rathouz PJ, McBurnett K. Waxing and waning in concert: dynamic comorbidity of conduct disorder with other disruptive and emotional problems over 7 years among clinic-referred boys. J Abnorm Psychol. 2002;111:556-67. https://doi. org/10.1037/0021-843X.111.4.556.

114. Loeber R, Keenan K. Interaction between conduct disorder and its comorbid conditions: effects of age and gender. Clin Psychol Rev. 1994;14:497-523. https://doi.org/10.1016/0272-7358(94)90015-9.

115. Verhulst FC, Eussen ML, Berden GF, Sanders-Woudstra J, van der Ende J. Pathways of problem behaviors from childhood to adolescence. J Am Acad Child Adolesc Psychiatry. 1993;32:388-96. https://doi. org/10.1097/00004583-199303000-00021.

116. Pine DS, Cohen E, Cohen P, Brook JS. Social phobia and the persistence of conduct problems. J Child Psychol Psychiatry. 2000;41:657-65. https://doi.org/10.1017/S0021963099005764.

117. Lansford JE, Malone PS, Stevens KI, Dodge KA, Bates JE, Pettit GS. Developmental trajectories of externalizing and internalizing behaviors: factors underlying resilience in physically abused children. Dev Psychopathol. 2006;18:35-55. https://doi.org/10.1017/S0954579406060032.

118. Mesman J, Bongers IL, Koot HM. Preschool developmental pathways to preadolescent internalizing and externalizing problems. J Child Psychol Psychiatry. 2001;42:679-89. https://doi.org/10.1111/1469-7610.00763.

119. Olson SL, Brodfeld PL. Assessment of peer rejection and externalizing behavior problems in preschool boys: a short-term longitudinal study. J Abnorm Child Psychol. 1991;19:493-503. https://doi.org/10.1007/ BF00919091.

120. Gazelle H, Ladd GW. Anxious solitude and peer exclusion: a diathesisstress model of internalizing trajectories in childhood. Child Dev. 2003;74:257-78. https://doi.org/10.1111/1467-8624.00534.

121. Larson RW, Raffaelli M, Richards MH, Ham M, Jewell L. Ecology of depression in late childhood and early adolescence: a profile of daily states and activities. J Abnorm Psychol. 1990;99:92-102. https://doi. org/10.1037/0021-843X.99.1.92.

122. Hymel S, Rubin KH, Rowden L, LeMare L. Children's peer relationships: longitudinal prediction of internalizing and externalizing problems from middle to late childhood. Child Dev. 1990;61:2004-21. https://doi. org/10.2307/1130854.

123. Cole DA, Martin JM, Powers B, Truglio R. Modeling causal relations between academic and social competence and depression: a multitrait-multimethod longitudinal study of children. J Abnorm Psychol. 1996;105:258-70. https://doi.org/10.1037/0021-843X.105.2.258

124. Dalley MB, Bolocofsky DN, Karlin NJ. Teacher-ratings and self-ratings of social competency in adolescents with low- and high-depressive symptoms. J Abnorm Child Psychol. 1994;22:477-85. https://doi. org/10.1007/BF02168086.

125. Obradovic J, Burt KB, Masten AS. Testing a dual cascade model linking competence and symptoms over 20 years from childhood to adulthood. J Clin Child Adolesc Psychol. 2010;39:90-102. https://doi. org/10.1080/15374410903401120.

126. Coie J, Terry R, Lenox K, Lochman J, Hyman C. Childhood peer rejection and aggression as predictors of stable patterns of adolescent disorder. Dev Psychopathol. 1995;7:697-713. https://doi.org/10.1017/ S0954579400006799.

127. Crijnen AA, Achenbach TM, Verhulst FC. Comparisons of problems reported by parents of children in 12 cultures: total problems, externalizing, and internalizing. J Am Acad Child Adolesc Psychiatry. 1997;36:1269-77. https://doi. org/10.1097/00004583-199709000-00020.

128. Fanti KA, Panayiotou G, Fanti S. Associating parental to child psychological symptoms: investigating a transactional model of development. J Emot Behav Disord. 2013;21:193-210. https://doi. org/10.1177/1063426611432171.

129. Rescorla L, Achenbach TM, Ivanova MY, Dumenci L, Almqvist F, Bilenberg $N$, et al. Epidemiological comparisons of problems and positive qualities reported by adolescents in 24 countries. J Consult Clin Psychol. 2007;75:351-8. https://doi.org/10.1037/0022-006X.75.2.351.

130. Benenson JF, Markovits H, Roy R, Denko P. Behavioural rules underlying learning to share: effects of development and context. Int J Behav Dev. 2003;27:116-21. https://doi.org/10.1080/01650250244000119.

131. Dunn J, Cutting AL. Understanding others, and individual differences in friendship interactions in young children. Soc Dev. 1999:8:201-19. https://doi.org/10.1111/1467-9507.00091.

132. Göncü A. Development of intersubjectivity in the dyadic play of preschoolers. Early Child Res Q. 1993;8:99-116. https://doi.org/10.1016/ S0885-2006(05)80100-0.

133. Watson AC, Nixon CL, Wilson A, Capage L. Social interaction skills and theory of mind in young children. Dev Psychol. 1999;35:386-91. https:// doi.org/10.1037/0012-1649.35.2.386.

134. Cole PM, Teti LO, Zahn-Waxler C. Mutual emotion regulation and the stability of conduct problems between preschool and early school age. Dev Psychopathol. 2003;15:1-18. https://doi.org/10.1017/ S0954579403000014.

135. Stright AD, Gallagher KC, Kelley K. Infant temperament moderates relations between maternal parenting in early childhood and children's adjustment in first grade. Child Dev. 2008;79:186-200. https://doi. org/10.1111/j.1467-8624.2007.01119.x.

136. Eisenberg N, Fabes RA, Spinrad TL. Prosocial development. In: Eisenberg N, Damon W, Lerner RM, editors. Handbook of child psychology, Social, emotional, and personality development, vol. 3. 6th ed. Hoboken: Wiley; 2006. p. 646-718.

137. NICHD Early Child Care Research Network. Early child care and children's development prior to school entry: results from the NICHD study of early child care. Am Educ Res J. 2002;39:133-64. https://doi. org/10.3102/00028312039001133.

138. Vazsonyi AT, Huang L. Where self-control comes from: on the development of self-control and its relationship to deviance over time. Dev Psychol. 2010;46:245-57. https://doi.org/10.1037/a0016538.

139. Tichovolsky MH, Arnold DH, Baker CN. Parent predictors of changes in child behavior problems. J Appl Dev Psychol. 2013;34:336-45. https:// doi.org/10.1016/j.appdev.2013.09.001.

140. Parke RD, Buriel R. Socialisation in the family: ethnic and ecological perspective. In: Damon W, Eisenberg N, editors. Handbook of child psychology. Social, emotional and personality development, vol. 3. 5th ed. New York: Wiley; 1998. p. 463-552.

141. Masten A, Coatsworth J. The development of competence in favorable and unfavorable environments: lessons from research on successful children. Am Psychol. 1998;53:205-20. https://doi. org/10.1037/0003-066X.53.2.205.

142. Zhou Q, Eisenberg N, Losoya SH, Fabes RA, Reiser M, Guthrie IK, et al. The relations of parental warmth and positive expressiveness to children's empathy-related responding and social functioning: a longitudinal study. Child Dev. 2002;73:893-915.

143. Barnett MA, Gustafsson H, Deng M, Mills-Koonce WR, Cox M. Bidirectional associations among sensitive parenting, language development, 
and social competence. Infant Child Dev. 2012;21:374-93. https://doi. org/10.1002/icd. 1750

144. Finger B, Eiden RD, Edwards EP, Leonard KE, Kachadourian L. Marital aggression and child peer competence: a comparison of three conceptual models. Pers Relatsh. 2010;17:357-76. https://doi. org/10.1111/j.1475-6811.2010.01284.x.

145. El-Sheikh M, Buckhalt J, Mize J, Acebo C. Marital conflict and disruption of children's sleep. Child Dev. 2006;77:31-43. https://doi. org/10.1111/j.1467-8624.2006.00854.x.

146. Cummings EM, Goeke-Morey MC, Papp LM. Everyday marital conflict and child aggression. J Abnorm Child Psychol. 2004;32:191-202. https://doi.org/10.1023/B:JACP.0000019770.13216.be.

147. Grych JH, Fincham FD. Children's appraisals of marital conflict: initial investigations of the cognitive-contextual framework. Child Dev. 1993;64:215-30. https://doi.org/10.2307/1131447.

148. Goodman SH, Barfoot B, Frye AA, Belli AM. Dimensions of marital conflict and children's social problem-solving skills. J Fam Psychol. 1999;13:33-45. https://doi.org/10.1037/0893-3200.13.1.33.

149. Grych JH, Fincham FD. Marital conflict and children's adjustment: a cognitive-contextual framework. Psychol Bull. 1990;108:267-90. https:// doi.org/10.1037/0033-2909.108.2.267.

150. McCoy K, Cummings EM, Davies PT. Constructive and destructive marital conflict, emotional security and children's prosocial behavior. J Child Psychol Psychiatry. 2009;50:270-9. https://doi. org/10.1111/j.1469-7610.2008.01945.x

151. Lengua $\sqcup$, Honorado E, Bush NR. Contextual risk and parenting as predictors of effortful control and social competence in preschool children. J Appl Dev Psychol. 2007;28:40-55. https://doi.org/10.1016/j. appdev.2006.10.001.

152. Ahrons CR. The continuing coparental relationship between divorced spouses. Am J Orthopsychiatry. 1981;51:415-28. https://doi. org/10.1111/j.1939-0025.1981.tb01390.x.

153. Ahrons CR, Tanner JL. Adult children and their fathers: relationship changes 20 years after parental divorce. Fam Relat. 2003;52:340-51. https://doi.org/10.1111/j.1741-3729.2003.00340.x.

154. Bonach K, Sales E, Koeske G. Gender differences in perceptions of coparenting quality among expartners. J Divorce Remarriage. 2005:43:1-28. https://doi.org/10.1300/J087v43n01_01.

155. Frick PJ. The Alabama parenting questionnaire. Alabama: University of Alabama; 1991.

156. Shelton KK, Frick PJ, Wootton J. Assessment of parenting practices in families of elementary school-age children. J Clin Child Psychol. 1996;25:317-29. https://doi.org/10.1207/s15374424jccp2503_8.

157. Frick PJ, Dantagnan AL. Predicting the stability of conduct problems in children with and without callous-unemotional traits. J Child Fam Stud. 2005;14:469-85. https://doi.org/10.1007/s10826-005-7183-1.

158. Anme T, Shinohara R, Sugisawa Y, Tanaka E, Watanabe T, Hoshino T. Validity and reliability of the Social Skill Scale (SSS) as an index of social competence for preschool children. J Health Sci. 2013;3:5-11. https:// doi.org/10.5923/j.health.20130301.02.

159. Takahashi Y, Okada K, Hoshino T, Anme T. Social skills of preschoolers: stability of factor structures and predictive validity from a nationwide cohort study in Japan. Jpn J Educ Psychol. 2008;56:81-92. https://doi. org/10.5926/jjep1953.56.1_81.

160. Takahashi Y, Okada K, Hoshino T, Anme T. Developmental trajectories of social skills during early childhood and links to parenting practices in a Japanese sample. PLOS ONE. 2015;10:e0135357. https://doi. org/10.1371/journal.pone.0135357.

161. Burt KB, Roisman Gl. Competence and psychopathology: cascade effects in the NICHD study of early child care and youth development. Dev Psychopathol. 2010;22:557-67. https://doi.org/10.1017/ S0954579410000271.

162. NICHD Early Child Care Research Network. Fathers' and mothers' parenting behavior and beliefs as predictors of children's social adjustment in the transition to school. J Fam Psychol. 2004;18:628-38. https://doi. org/10.1037/0893-3200.18.4.628.

163. Goodman R. The strengths and difficulties questionnaire: a research note. J Child Psychol Psychiatry. 1997;38:581-6. https://doi. org/10.1111/j.1469-7610.1997.tb01545.x.

164. Goodman R. The extended version of the Strengths and Difficulties Questionnaire as a guide to child psychiatric caseness and consequent burden. J Child Psychol Psychiatry. 1999;40:791-9. https://doi. org/10.1111/1469-7610.00494

165. Goodman R, Ford T, Simmons H, Gatward R, Meltzer H. Using the Strengths and Difficulties Questionnaire (SDQ) to screen for child psychiatric disorders in a community sample. Int Rev Psychiatry. 2003;15:166-72. https://doi.org/10.1080/0954026021000046128.

166. Matsuishi T, Nagano M, Araki Y, Tanaka Y, Iwasaki M, Yamashita Y, et al. Scale properties of the Japanese version of the Strengths and Difficulties Questionnaire (SDQ): a study of infant and school children in community samples. Brain Dev. 2008;30:410-5. https://doi.org/10.1016/j. braindev.2007.12.003.

167. Goodman A, Lamping DL, Ploubidis GB. When to use broader internalising and externalising subscales instead of the hypothesised five subscales on the Strengths and Difficulties Questionnaire (SDQ): data from British parents, teachers and children. J Abnorm Child Psychol. 2010;38:1179-91. https://doi.org/10.1007/s10802-010-9434-x.

168. Bentler PM. Comparative fit indexes in structural models. Psychol Bull. 1990;107:238-46. https://doi.org/10.1037/0033-2909.107.2.238.

169. Bollen KA. Overall fit in covariance structure models: two types of sample size effects. Psychol Bull. 1990;107:256-9. https://doi. org/10.1037/0033-2909.107.2.256.

170. Steiger $\mathrm{JH}$. Structural model evaluation and modification: an interval estimation approach. Multivariate Behav Res. 1990;25:173-80. https:// doi.org/10.1207/s15327906mbr2502_4.

171. Byrne BM. Structural equation modeling with LISREL, PRELIS, and SIMPLIS: basic concepts, applications, and programming. Mahwah: Lawrence Erlbaum Associates; 1998.

172. Yeung WJ, Linver MR, Brooks-Gunn JB. How money matters for young children's development: parental investment and family processes. Child Dev. 2002;73:1861-79. https://doi.org/10.1111/1467-8624. t01-1-00511.

173. Conger RD, Dogan SJ. Social class and socialization in families. In: Grusec J, Hastings P, editors. Handbook of socialization: theory and research. New York: Guilford; 2007. p. 433-60.

174. Linver MR, Brooks-Gunn J, Kohen D. Family processes as pathways from income to young children's development. Dev Psychol. 2002;38:719-34

175. Becker GS, Tomes N. Human capital and the rise and fall of families. J Labor Econ. 1986;4:1-47. https://doi.org/10.1086/298118.

176. Mayer S. What money can't buy: family income and children's life chances. Cambridge: Harvard University Press; 1997.

177. Brown JE, Mann L. The relationship between family structure and process variables and adolescent decision making. J Adolesc. 1990;13:2537. https://doi.org/10.1016/0140-1971(90)90039-A.

178. Van der Slik FWP, De Graaf ND, Gerris JRM. Conformity to parental rules: asymmetric influences of father's and mother's levels of education. Eur Sociol Rev. 2002:18:489-502. https://doi.org/10.1093/esr/18.4.489.

179. Fulmer KA. Parents' decision-making strategies when selecting child care: effects of parental awareness, experience, and education. Child Youth Care Forum. 1997;26:391-409. https://doi.org/10.1007/ BF02589503.

180. Klebanov PK, Brooks-Gunn J, Duncan GJ. Does neighborhood and family poverty affect mothers' parenting, mental health, and social support? J Marriage Fam. 1994;56:441-55. https://doi.org/10.2307/353111.

181. Belsky J, Crnic K, Gable S. The determinants of coparenting in families with toddler boys: spousal differences and daily hassles. Child Dev. 1995;66:629-42. https://doi.org/10.2307/1131939.

182. McHale JP. Coparenting and triadic interactions during infancy: the roles of marital distress and child gender. Dev Psychol. 1995;31:985-96. https://doi.org/10.1037/0012-1649.31.6.985.

183. Barkin S, Scheindlin B, Ip E, Richardson I, Finch S. Determinants of parental discipline practices: a national sample from primary care practices. Clin Pediatr (Phila). 2007:46:64-9. https://doi. org/10.1177/0069922806292644.

184. Frías-Armenta M, McCloskey LA. Determinants of harsh parenting in Mexico. J Abnorm Child Psychol. 1998;26:129-39. https://doi.org/10.102 3/A:1022621922331.

185. Jackson S, Thompson RA, Christiansen EH, Colman RA, Wyat J, Buckendahl CW, et al. Predicting abuse-prone parental attitudes and discipline practices in a nationally representative sample. Child Abuse Negl. 1999;23:15-29. https://doi.org/10.1016/S0145-2134(98)00108-2. 
186. Tamis-LeMonda CS, Shannon JD, Cabrera NJ, Lamb ME. Fathers and mothers at play with their 2- and 3-year-olds: contributions to language and cognitive development. Child Dev. 2004;75:1806-20. https://doi. org/10.1111/j.1467-8624.2004.00818.x.

187. Bornstein $\mathrm{MH}$, Bradley $\mathrm{RH}$, editors. Socioeconomic status, parenting, and child development. Mahwah: Erlbaum; 2003.

188. Huston AC, Rosenkrantz Aronson S. Mothers' time with infant and time in employment as predictors of mother-child relationships and children's early development. Child Dev. 2005;76:467-82. https://doi. org/10.1111/j.1467-8624.2005.00857.x.

189. Sohr-Preston SL, Scaramella LV, Martin MJ, Neppl TK, Ontai L, Conger R. Parental socioeconomic status, communication, and children's vocabulary development: a third-generation test of the family investment model. Child Dev. 2013;84:1046-62. https://doi.org/10.1111/ cdev.12023.

190. Hoff E. The specificity of environmental influence: socioeconomic status affects early vocabulary development via maternal speech. Child Dev. 2003;74:1368-78. https://doi.org/10.1111/1467-8624.00612.

191. Guo G, Harris KM. The mechanisms mediating the effects of poverty on children's intellectual development. Demography. 2000;37:431-47. https://doi.org/10.1353/dem.2000.0005.

192. Bradley RH, Corwyn RF. Age and ethnic variations in family process mediators of SES. In: Bornstein MH, Bradley RH, editors. Socioeconomic status, parenting, and child development. Mahwah: Erlbaum; 2003. p. 161-88.

193. John A, Halliburton A, Humphrey J. Child-mother and child-father play interaction patterns with preschoolers. Early Child Dev Care. 2013;183:483-97. https://doi.org/10.1080/03004430.2012.711595.

194. Carson JL, Burks VM, Parke RD. Parent-child physical play: determinants and consequences. In: MacDonald KB, editor. Parent-child play. Albany: SUNY Press; 1993. p. 197-220.

195. Kerns K, Barth JM. Attachment and play: convergence across components of parent-child relationships and their relations to peer competence. J Soc Pers Relatsh. 1995;12:243-60. https://doi. org/10.1177/0265407595122006.

196. Lindsey EW, Mize J, Pettit GS. Mutuality in parent-child play: consequences for children's peer competence. J Soc Pers Relatsh. 1997;14:523-38. https://doi.org/10.1177/0265407597144007.

197. Barth JM, Parke RD. Parent-child relationship influences on children's transition to school. Merrill-Palmer Q. 1993;39:173-95.

198. Carson JL, Parke RD. Reciprocal negative affect in parent-child interactions and children's peer competency. Child Dev. 1996;67:2217-26. https://doi.org/10.2307/1131619.

199. Sandseter EBH. 'It tickles in my tummy!' Understanding children's risktaking in play through reversal theory. J Early Child Res. 2010;8:67-88. https://doi.org/10.1177/1476718x09345393.

200. Flanders JL, Leo V, Paquette D, Pihl RO, Séguin JR. Rough-and-tumble play and the regulation of aggression: an observational study of father-child play dyads. Aggress Behav. 2009;35:285-95. https://doi. org/10.1002/ab.20309.

201. Flanders J, Simard M, Paquette D, Parent S, Vitaro F, Pihl R, et al. Rough-and-tumble play and the development of physical aggression and emotion regulation: a five-year follow-up study. J Fam Violence. 2010;25:357-67. https://doi.org/10.1007/s10896-009-9297-5.

202. Fletcher R, StGeorge J, Freeman E. Rough and tumble play quality: theoretical foundations for a new measure of father-child interaction. Early Child Dev Care. 2013;183:746-59. https://doi.org/10.1080/030044 30.2012.72343.

203. Martin A, Ryan RM, Brooks-Gunn J. When fathers'supportiveness matters most: maternal and paternal parenting and children's school readiness. J Fam Psychol. 2010;24:145-55. https://doi.org/10.1037/a0018073.

204. Augustine JM, Cavanagh SE, Crosnoe R. Maternal education, early child care and the reproduction of advantage. Soc Forces. 2009;88:1-29. https://doi.org/10.1353/sof.0.0233.

205. Stams GJ, Juffer F, van IJzendoorn MH. Maternal sensitivity, infant attachment, and temperament in early childhood predict adjustment in middle childhood: the case of adopted children and their biologically unrelated parents. Dev Psychol. 2002;38:806-21. https://doi. org/10.1037/0012-1649.38.5.806

206. Snow C. Enhancing literacy development: programs and research perspectives. Malden: Blackwell Publishing; 1994.
207. Whitehurst GJ, Fischel JE. Practitioner review: early developmental language delay: what, if anything, should the clinician do about it? J Child Psychol Psychiatry. 1994;35:613-48. https://doi. org/10.1111/j.1469-7610.1994.tb01210.x.

208. Guralnick M. Family and child influences on the peer-related social competence of young children with developmental delays. Ment Retard Dev Disabil Res Rev. 1999;5:21-9. https://doi.org/10.1002/ (SICI) 1098-2779(1999)5:13.3.CO;2-F.

209. Cummings EM, Davies PT. Effects of marital conflict on children: recent advances and emerging themes in process-oriented research. J Child Psychol Psychiatry. 2002;43:31-63. https://doi. org/10.1111/1469-7610.00003.

210. Grych JH, Fincham FD, Jouriles EN, McDonald R. Interparental conflict and child adjustment: testing the mediational role of appraisals in the cognitive-contextual framework. Child Dev. 2000;71:1648-61. https:// doi.org/10.1111/1467-8624.00255.

211. El-Sheikh M, Elmore-Staton L. The link between marital conflict and child adjustment: parent-child conflict and perceived attachments as mediators, potentiators, and mitigators of risk. Dev Psychopathol. 2004;16:631-48. https://doi.org/10.1017/S0954579404004705.

212. Camisasca E, Miragoli S, Di Blasio P. Families with distinct levels of marital conflict and child adjustment: which role for maternal and paternal stress? J Child Fam Stud. 2016;2015(25):733-45. https://doi.org/10.1007/ s10826-015-0261-0.

213. Marks CR, Glaser BA, Glass JB, Horne AM. Effects of witnessing severe marital discord on children's social competence and behavioral problems. Fam J. 2001;9:94-101. https://doi. org/10.1177/1066480701092002.

214. McCloskey LA, Stuewig J. The quality of peer relationships among children exposed to family violence. Dev Psychopathol. 2001;13:83-96. https://doi.org/10.1017/S0954579401001067.

215. Schudlich TDDR, Shamir H, Cummings EM. Marital conflict, children's representations of family relationships, and childrens dispositions towards peer conflict strategies. Soc Dev. 2004;13:171-92. https://doi. org/10.1111/j.1467-9507.2004.000262.x.

216. Dadds MR, Atkinson E, Turner C, Blums GJ, Lendich B. Family conflict and child adjustment: evidence for a cognitive-contextual model of intergenerational transmission. J Fam Psychol. 1999;13:194-208. https:// doi.org/10.1037/0893-3200.13.2.194.

217. Bandura A. Self-efficacy: toward a unifying theory of behavioral change. Psychol Rev. 1977;84:191-215. https://doi. org/10.1037/0033-295X.84.2.191.

218. Frankel LA, Hughes SO, O'Connor TM, Power TG, Fisher JO, Hazen NL. Parental influences on children's self-regulation of energy intake: insights from developmental literature on emotion regulation. J Obes. 2012;2012:327259. https://doi.org/10.1155/2012/327259.

219. Hovell MF, Schumaker JB, Sherman JA. A comparison of parents' models and expansions in promoting children's acquisition of adjectives. J Exp Child Psychol. 1978;25:41-57. https://doi. org/10.1016/0022-0965(78)90037-1.

220. Rubin KH, Hastings $P$, Chen $X$, Stewart S, McNichol K. Intrapersonal and maternal correlates of aggression, conflict, and externalizing problems in toddlers. Child Dev. 1998;69:1614-29. https://doi. org/10.2307/1132135

221. Cassidy J, Parke RD, Butkovsky L, Braungart JM. Family-peer connections: the roles of emotional expressiveness within the family and children's understanding of emotions. Child Dev. 1992;63:603-18. https:// doi.org/10.2307/1131349.

222. Brody $\mathrm{GH}$, Henderson RW. Effects of multiple model variations and rationale provision on the moral judgments and explanations of young children. Child Dev. 1977:48:1117-20. https://doi.org/10.2307/1128372.

223. Najaka SS, Gottfredson DC, Wilson DB. A meta-analytic inquiry into the relationship between selected risk factors and problem behavior. Prev Sci. 2001;2:257-71. https://doi.org/10.1023/A:1013610115351.

224. Rose-Krasnor $L$. The nature of social competence: a theoretical review. Soc Dev. 1997;6:111-35. https://doi.org/10.1111/j.1467-9507.1997. tb00097.x.

225. Han SS, Weisz JR, Weiss B. Specificity of relations between children's control-related beliefs and internalizing and externalizing psychopathology. J Consult Clin Psychol. 2001;69:240-51. 
226. Shonk S, Cicchetti D. Maltreatment, competency deficits, and risk for academic and behavioral maladjustment. Dev Psychol. 2001;37:3-17. https://doi.org/10.1037/0012-1649.37.1.3.

227. Ladd GW. Peer relationships and social competence during early and middle childhood. Annu Rev Psychol. 1999;50:333-59. https://doi. org/10.1146/annurev.psych.50.1.333

228. Ladd GW, Kochenderfer BJ, Coleman CC. Friendship quality as a predictor of young children's early school adjustment. Child Dev. 1996;67:1103-18. https://doi.org/10.2307/1131882.

229. Bornstein MH, Hahn C, Haynes OM. Social competence, externalizing, and internalizing behavioral adjustment from early childhood through early adolescence: developmental cascades. Dev Psychopathol. 2010;22:717-35. https://doi.org/10.1017/S0954579410000416

230. Walker HM, Stieber S. Teacher ratings of social skills as longitudinal predictors of long-term arrest status in a sample of at-risk males. Behav Disord. 1998;23:222-30.

231. Webster-Stratton C, Hammond M. Conduct problems and level of social competence in head start children: prevalence, pervasiveness, and associated risk factors. Clin Child Fam Psychol Rev. 1998;1:101-24. https://doi.org/10.1023/A:1021835728803.

232. Webster-Stratton C, Lindsay DW. Social competence and conduct problems in young children: issues in assessment. J Clin Child Psychol. 1999;28:25-43. https://doi.org/10.1207/s15374424jccp2801_3.

233. Shaw DS, Keenan K, Vondra JI, Delliquardi E, Giovannelli J. Antecedents of preschool children's internalizing problems: a longitudinal study of low-income families. J Am Acad Child Adolesc Psychiatry. 1997;36:1760-7. https://doi.org/10.1097/00004583-199712000-00025

234. Eisenberg N, Fabes RA, Murphy B, Maszk P, Smith M, Karbon M. The role of emotionality and regulation in children's social functioning: a longitudinal study. Child Dev. 1995;66:1360-84. https://doi. org/10.1111/j.1467-8624.1995.tb00940.x.

235. Valente E Jr, Dodge KA. Evaluation of prevention programs for children. In: Weissberg RP, Gullotta TP, Hampton RL, Ryan BA, Adams GR, editors. Issues in children's and families'lives. Healthy children 2010: establishing preventive services, vol. 9. Thousand Oaks: Sage; 1997. p. 183-218.

236. Cole DA, Maxwell SE. Testing mediational models with longitudinal data: questions and tips in the use of structural equation modeling. J Abnorm Psychol. 2003;112:558-77. https://doi. org/10.1037/0021-843X.112.4.558.

237. Maxwell SE, Cole DA, Mitchell MA. Bias in cross-sectional analyses of longitudinal mediation: partial and complete mediation under an autoregressive model. Multivariate Behav Res. 2011;46:816-41. https:// doi.org/10.1080/00273171.2011.606716.

238. Campbell SB, Pierce EW, March CL, Ewing LJ. Noncompliant behavior, overactivity, and family stress as predictors of negative maternal control with preschool children. Dev Psychopathol. 1991;3:175-90. https://doi. org/10.1017/S0954579400000067.

239. Solantaus T, Leinonen J, Punamaki R. Children's mental health in times of economic recession: replication and extension of the family economic stress model in Finland. Dev Psychol. 2004;40:412-29. https:// doi.org/10.1037/0012-1649.40.3.412.

240. Elgar FJ, McGrath PJ, Waschbusch DA, Stewart SH, Curtis LJ. Mutual influences on maternal depression and child adjustment problems. Clin Psychol Rev. 2004;24:441-59. https://doi.org/10.1016/j. cpr.2004.02.002.

241. Feldman R. Mutual influences between child emotion regulation and parent-child reciprocity support development across the first 10 years of life: implications for developmental psychopathology. Dev Psychopathol. 2015;27:1007-23. https://doi.org/10.1017/S0954579415000656.

242. La Greca AM, Silverman WK. Parent reports of child behavior problems: bias in participation. J Abnorm Child Psychol. 1993;21:89-101. https:// doi.org/10.1007/BF00910491.

243. Gelfand DM, Teti DM. The effects of maternal depression on children. Clin Psychol Rev. 1990;10:329-53. https://doi. org/10.1016/0272-7358(90)90065-l.

244. Johnston D, Propper C, Pudney S, Shields M. Child mental health and educational attainment: multiple observers and the measurement error problem. J Appl Econom. 2014;29:880-900. https://doi.org/10.1002/ jae.2359.

245. Brown JD, Wissow LS, Gadomski A, Zachary C, Bartlett E, Horn I. Parent and teacher mental health ratings of children using primary-care services: interrater agreement and implications for mental health screening. Ambul Pediatr. 2006;6:347-51. https://doi.org/10.1016/j. ambp.2006.09.004.

246. Majdandžić M, de Vente W, Bögels SM. Challenging parenting behavior from infancy to toddlerhood: etiology, measurement, and differences between fathers and mothers. Infancy. 2016;21:423-52. https://doi. org/10.1111/infa.12125.

247. Tavassolie T, Dudding S, Madigan AL, Thorvardarson E, Winsler A. Differences in perceived parenting style between mothers and fathers: implications for child outcomes and marital conflict. J Child Fam Stud. 2016;25:2055-68. https://doi.org/10.1007/s10826-016-0376-y.

248. Schafer J, Caetano R, Clark CL. Rates of intimate partner violence in the United States. Am J Public Health. 1998;88:1702-4. https://doi. org/10.2105/AJPH.88.11.1702.

249. Cabrera NJ, Fitzgerald HE, Bradley RH, Roggman L. The ecology of father-child relationships: an expanded model. J Fam Theory Rev. 2014;6:336-54. https://doi.org/10.1111/jttr.12054.

250. O'Leary SG, Vidair HB. Marital adjustment, child-rearing disagreements, and overreactive parenting: predicting child behavior problems. J Fam Psychol. 2005;19:208-16. https://doi.org/10.1037/0893-3200.19.2.208.

251. Fagan J, Day R, Lamb ME, Cabrera NJ. Should researchers conceptualize differently the dimensions of parenting for fathers and mothers? J Fam Theory Rev. 2014;6:390-405. https://doi.org/10.1111/jttr.12044.

252. Najman JM, Williams GM, Nikles J, Spence S, Bor W, O'Callaghan M, et al. Bias influencing maternal reports of child behaviour and emotional state. Soc Psychiatry Psychiatr Epidemiol. 2001;36:186-94. https://doi. org/10.1007/s001270170062.

253. DeSocio J, Hootman J. Children's mental health and school success. J Sch Nurs. 2004;20:189-96. https://doi.org/10.1177/10598405040200040 201.

254. Goodman R, Renfrew D, Mullick M. Predicting type of psychiatric disorder from Strengths and Difficulties Questionnaire (SDQ) scores in child mental health clinics in London and Dhaka. Eur Child Adolesc Psychiatry. 2000;9:129-34. https://doi.org/10.1007/s007870050008.

255. Rhee SH, Waldman ID. Genetic and environmental influences on antisocial behavior: a meta-analysis of twin and adoption studies. Psychol Bull. 2002;128:490-529. https://doi.org/10.1037/0033-2909.128.3.490.

256. Bouchard TJ. Genetic influence on human psychological traits: a survey. Curr Dir Psychol Sci. 2004;13:148-51. https://doi. org/10.1111/j.0963-7214.2004.00295.x

257. DiLalla LF, Gottesman II. Biological and genetic contributors to violence—Widom's untold tale. Psychol Bull. 1991;109:125-9. https://doi org/10.1037/0033-2909.109.1.125.

258. Moffitt TE, Caspi A, Rutter M. Strategy for investigating interactions between measured genes and measured environments. Arch Gen Psychiatry. 2005;62:473-81. https://doi.org/10.1001/archpsyc.62.5.473.

259. Boyce WT, Ellis BJ. Biological sensitivity to context: i. an evolutionarydevelopmental theory of the origins and functions of stress reactivity. Dev Psychopathol. 2005;17:271-301. https://doi.org/10.1017/ S0954579405050145.

260. Pluess M, Belsky J. Differential susceptibility to parenting and quality child care. Dev Psychol. 2010;46:379-90. https://doi.org/10.1037/ a0015203.

261. Plomin R, Crabbe J. Dna. Psychol Bull. 2000;126:806-28. https://doi. org/10.1037/0033-2909.126.6.806

262. McBride Murry V, Berkel C, Gaylord-Harden NK, CopelandLinder N, Nation M. Neighborhood poverty and adolescent development. J Res Adolesc. 2011;21:114-28. https://doi. org/10.1111/j.1532-7795.2010.00718.x.

263. Sonenstein FL. Introducing the well-being of adolescents in vulnerable environments study: methods and findings. J Adolesc Health. 2014;55:S1-3. https://doi.org/10.1016/j.jadohealth.2014.09.008.

264. Wickrama KAS, Noh S. The long arm of community: the influence of childhood community contexts across the early life course. J Youth Adolesc. 2010;39:894-910. https://doi.org/10.1007/s10964-009-9411-2.

265. Brooks-Gunn J, Duncan GJ, Klebanov PK, Sealand N. Do neighborhoods influence child and adolescent development? Am J Sociol. 1993;99(2):353-95. https://doi.org/10.1086/230268. 